\title{
Second-to-Fourth Digit Ratio (2D:4D) in Psychiatric Disorders: A Systematic Review of Case-control Studies
}

\author{
Laura Fusar-Poli ${ }^{1, *}$, Alessandro Rodolico ${ }^{1, *}$, Serena Sturiale', Bianca Carotenuto ${ }^{1}$, Antimo Natale', \\ Davide Arillotta ${ }^{1}$, Spyridon Siafis ${ }^{2}$, Maria Salvina Signorelli ${ }^{1}$, Eugenio Aguglia ${ }^{1}$ \\ ${ }^{1}$ Department of Clinical and Experimental Medicine, Psychiatry Unit, University of Catania, Catania, Italy, ${ }^{2}$ Department of Psychiatry and \\ Psychotherapy, School of Medicine, Technical University of Munich, Munich, Germany
}

The second-to-fourth digit ratio (2D:4D) is an indirect, retrospective, non-invasive measure that correlates negatively with intrauterine exposure to testosterone. The present meta-analysis aimed to evaluate if 2D:4D differs between patients with psychiatric disorders and controls. In September 2019, we searched in Web of Knowledge, PsyclNFO, Embase, and CINHAL, and retrieved 619 papers. We finally included 43 case-control studies which compared the 2D:4D ratio of patients with autism spectrum disorder (ASD) $(n=16)$, schizophrenia $(n=8)$, gender non-conformity $(n=7)$, addictions $(n=5)$, attention deficit-hyperactivity disorder (ADHD) $(n=4)$, mood disorders $(n=2)$, and intellectual disability $(n=1)$ to non-clinical controls. Meta-analyses showed that, overall, psychiatric patients had lower 2D:4D than healthy controls $(n=43$, overall sample $=9,484$, mean difference $=-0.0056$, 95\% confidence interval from -0.0093 to $-0.002, \mathrm{I}^{2}=74 \%$ ), with more pronounced differences in the right hand, males, and children. Considering psychiatric disorders individually, significant differences were found in the ASD, ADHD, and addictions groups, in which 2D:4D was significantly lower than healthy controls. Conversely, the right hand of males with schizophrenia showed higher 2D:4D than healthy controls. No other significant differences were detected. Although our results need to be cautiously interpreted and find limited applications in clinical practice, they may suggest that 2D:4D is altered in some psychopathological conditions, underlining the role of prenatal exposure to sex steroids in the etiology of psychiatric disorders.

KEY WORDS: Meta-analysis; Mental disorders; Testosterone; Autism spectrum disorder; Attention deficit disorder with hyperactivity; Substance addiction.

\section{INTRODUCTION}

The second-to-fourth digit ratio (2D:4D) is a biological marker, defined as the ratio of the length of the index (second digit) to the length of the ring finger (fourth digit) of the same hand. 2D:4D is constant throughout life [1,2] and represents an indirect, retrospective, and non-invasive measure that correlates negatively with intrauterine exposure to testosterone, i.e., a lower 2D:4D is the result of increased levels of fetal testosterone $[3,4]$. Many debates

Received: May 7, 2020 / Revised: July 24, 2020

Accepted: July 26, 2020

Address for correspondence: Laura Fusar-Poli

Department of Clinical and Experimental Medicine, Psychiatry Unit, University of Catania, Via Santa Sofia 78, Catania 95123, Italy

E-mail: laura.fusarpoli@gmail.com

ORCID: https://orcid.org/0000-0002-5847-6947

*These authors contributed equally to this study as co-first authors. exist around the reasons why 2D:4D could be considered an indirect marker of the prenatal, but not the present, testosterone level [5] and even more strongly, a marker of the ratio between prenatal testosterone and estradiol levels. More evidence is provided by molecular genetic association studies, relating a polymorphism of the androgen receptor gene to individual differences in the 2D:4D ratio [6].

In humans, the 2D:4D ratio has been assumed to reflect the exposure to testosterone during the second trimester of gestation, because of the sex difference detectable in childhood, and because of postulated mechanisms regarding digit development [2]. Prenatal hormone exposure is critical for sexual differentiation and masculinization. In fact, males are exposed to higher levels of testosterone than females, particularly from about week 8 to 24 of gestation and week 2 to 26 of postnatal life [7]. This is con-

(c) This is an Open-Access article distributed under the terms of the Creative Commons Attribution Non-Commercial License (http://creativecommons.org/licenses/by-nc/4.0) which permits unrestricted non-commercial use, distribution, and reproduction in any medium, provided the original work is properly cited. 
firmed by the observation that the $2 \mathrm{D}: 4 \mathrm{D}$ ratio is sexually dimorphic: generally, females have a higher 2D:4D than males and this effect is more pronounced in the right hands, although the reasons still need to be clarified [8].

Digit ratio has been reported to correlate with a wide number of traits and conditions, ranging in almost every field of medicine, with particular regard to sex hormonesdependent conditions, i.e., breast cancer [9], prostate cancer [10,11], obesity [12], and osteoarthritis [13]. It has also been associated with physical characteristics, such as facial shape [14], sperm count [15], age of menarche [16], and penis size [17]. Of interest, scholars have also investigated the association between the 2D:4D ratio and behavioral features, such as aggression [18], stuttering [19], visuo-spatial ability [20], handedness [21], schizotypal personality [22], sporting ability [23], successful financial risk-taking [24], and sexual orientation [25].

Given the findings obtained in the field of behavioral sciences, over the last years, many researchers have sought to examine potential links between the 2D:4D ratio and psychiatric disorders, aiming to find a significant correlation between intrauterine exposure to testosterone and those conditions. Since the amount of available literature has been constantly growing, we aimed to perform a systematic review and meta-analysis to examine if the 2D:4D ratio consistently differed between people with psychiatric disorders and non-clinical controls. Second, we aimed to investigate potential mediators of 2D:4D differences, such as gender, age, and hand.

\section{METHODS}

\section{Search Strategy}

We followed the PRISMA Statement guidelines to perform a systematic search [26]. The protocol was registered on PROSPERO, an international database of prospectively registered systematic reviews in health and social care managed by the Centre for Reviews and Dissemination, University of York (Registration number: CRD42019124184).

In September 2019, we searched the following databases: Web of Knowledge ${ }^{S M}$ (including Web of Science, MEDLINE ${ }^{\circledR}, \mathrm{KCl}$ - Korean Journal Database, Russian Science Citation Index, and SciELO Citation Index), PsycINFO, Embase, and CINAHL. The complete search string can be found in the Supplementary Materials, Appendix 1 (available online) [27]. The search was not restricted to any lan- guage, reference type, or year of publication. The electronic search was supplemented by hand-searching of reference lists of the included review articles to identify any additional sources.

\section{Study Selection}

We selected all the studies published in English on peer-reviewed journals, which fulfilled the following inclusion criteria:

(1) Participants: Individuals of any age and gender, diagnosed with any psychiatric disorder according to valid international diagnostic criteria (e.g., Diagnostic and Statistical Manual of Mental Disorders; International Classification of Diseases), or with validated scales (e.g., Hamilton Rating Scale for depression and Positive and Negative Syndrome Scale for schizophrenia), or followed by clinics or mental health services. Studies with patients recruited through web-surveys or subjects divided into groups according to scores obtained at self-reported questionnaires were excluded.

(2) Controls: Individuals with no psychiatric disorders.

(3) Outcome: Measurement of 2D:4D ratio through direct or indirect tools, and availability of data.

(4) Study design: Case-control studies.

\section{Data Extraction}

Couples of researchers (SS, BC, AN, DA) independently reviewed and extracted the information from the included articles. Discrepancies were solved after consultation with a third reviewer (LF). We extracted data using a format which included:

(1) Study characteristics: author, year, country.

(2) Participants' characteristics: type of diagnosis, diagnostic tool (only for psychiatric patients), sample size, mean age, age range, proportion of males.

(3) 2D:4D measurement tool.

(4) Mean and standard deviation (SD) of the 2D:4D ratio. If reported in the studies, data were extracted separately for left and right hand, and for males and females.

We contacted study authors via e-mail to request missing data or for clarification, providing an individualized data table for reporting the requested information.

\section{Appraisal of Quality}

Quality of the included studies was assessed by two review authors (AR, DA) using the Newcastle-Ottawa qual- 
ity assessment scale for case-control studies [28]. Any discrepancy was solved after consultation with a third reviewer (LF). The Newcastle-Ottawa comprises eight items, categorized into three groups: the selection of the study groups; the comparability of the groups; and the ascertainment of either the exposure or outcome of interest for case-control or cohort studies, respectively. Stars awarded for each quality item serve as a quick visual assessment. Stars are awarded such that the highest quality studies are awarded up to nine stars [28].

\section{Statistical Analyses}

\section{Meta-analysis calculations}

The primary aim of this study was to compare the 2D:4D digit ratio in all psychiatric conditions, regardless of the hand measured and the gender of the included subjects. Most of the studies reported the means of 2D:4D divided by hand and gender. Some studies reported results only for the left or the right hand, while other studies reported aggregated data for left and right hands. Thus, we decided to combine the data to have a common estimate of the digit ratio, regardless of gender and hand. First, in order to combine the measure of right and left hand, we calculated the averaged means for left and right hands digit ratio. To avoid an underestimation of the SD, that might be the case in within-subjects data combination, we used the formula suggested by Borenstein et al. [29], setting as a correlation coefficient 0.8 , as proposed in previous literature. Then, we computed a weighted mean for each study, in order to combine males and females digit ratios, while we calculated SD according to the Cochrane Handbook formula for grouping independent samples [30]. In case SD was missing [31], we replaced it with the mean of the SD among the same diagnostic category (i.e., autism spectrum disorder, ASD).

\section{Effect size and heterogeneity}

We used mean differences (MD) as effect size, being the 2D:4D always measured in the same unit. Studies were pooled using a random-effects model since a consistent heterogeneity among observational studies was expected. Between-study heterogeneity was assessed using the $\mathbf{I}^{2}$ statistic. According to the Cochrane handbook, an $\mathrm{I}^{2}$ of $0-$ $40 \%$ represents a low heterogeneity, $\mathrm{I}^{2}$ of $30-60 \%$ is moderate heterogeneity, $\mathrm{I}^{2}$ of $50-90 \%$ indicates sub- stantial heterogeneity [30]. Small study effects as a proxy of publication bias were explored with contour-enhanced funnel plots for the visual detection of asymmetries. Egger's regression test was used to detect asymmetry in the funnel plots.

\section{Subgroup analyses}

For each psychiatric disorder, we conducted subgroup meta-analyses on males and females and left and right hands, separately. In the main analysis of the overall sample, we conducted a subgroup analysis also on children and adults. Chi-squared $\left(\chi^{2}\right)$ was used to test differences between subgroups.

Analyses were conducted using meta package (v.4.9-9) within the open-source software environment $R$ (v3.6). $\alpha$ was set at 0.05 .

\section{RESULTS}

\section{Characteristics of the Included Studies}

Our search yielded a total of 619 articles, while four additional papers were retreived from other sources. After duplicates removal, we screened the titles and abstracts of 399 papers and read the full texts of 96 papers. We finally included 43 articles, evaluating the 2D:4D ratio in patients with the following psychiatric diagnoses:

(1) Neurodevelopmental disorders, specifically attention deficit-hyperactivity disorder (ADHD; $n=4)$, ASD ( $n=$ 16), and intellectual disability (ID; $n=1$ )

(2) Schizophrenia $(n=8)$

(3) Addictions, specifically alcohol dependence $(n=3)$ and heroin dependence $(n=2)$

(4) Gender nonconformity, such as gender dysphoria, gender identity disorder, transsexualism, or transgenderism $(\mathrm{n}=7)$

(5) Mood disorders, specifically bipolar disorder ( $\mathrm{n}=$ 1) and depression $(n=1)$.

The study selection process and the reasons for exclusion are reported in the PRISMA Flow Diagram (Fig. 1).

\section{Neurodevelopmental disorders}

Twenty-one studies evaluated the 2D:4D ratio in neurodevelopmental disorders, such as ADHD, ASD, and ID. Thirteen studies were conducted in Europe, specifically in the United Kingdom, The Netherlands, Belgium, Germany, Greece, Slovak Republic, Sweden, and Turkey. Six stud- 


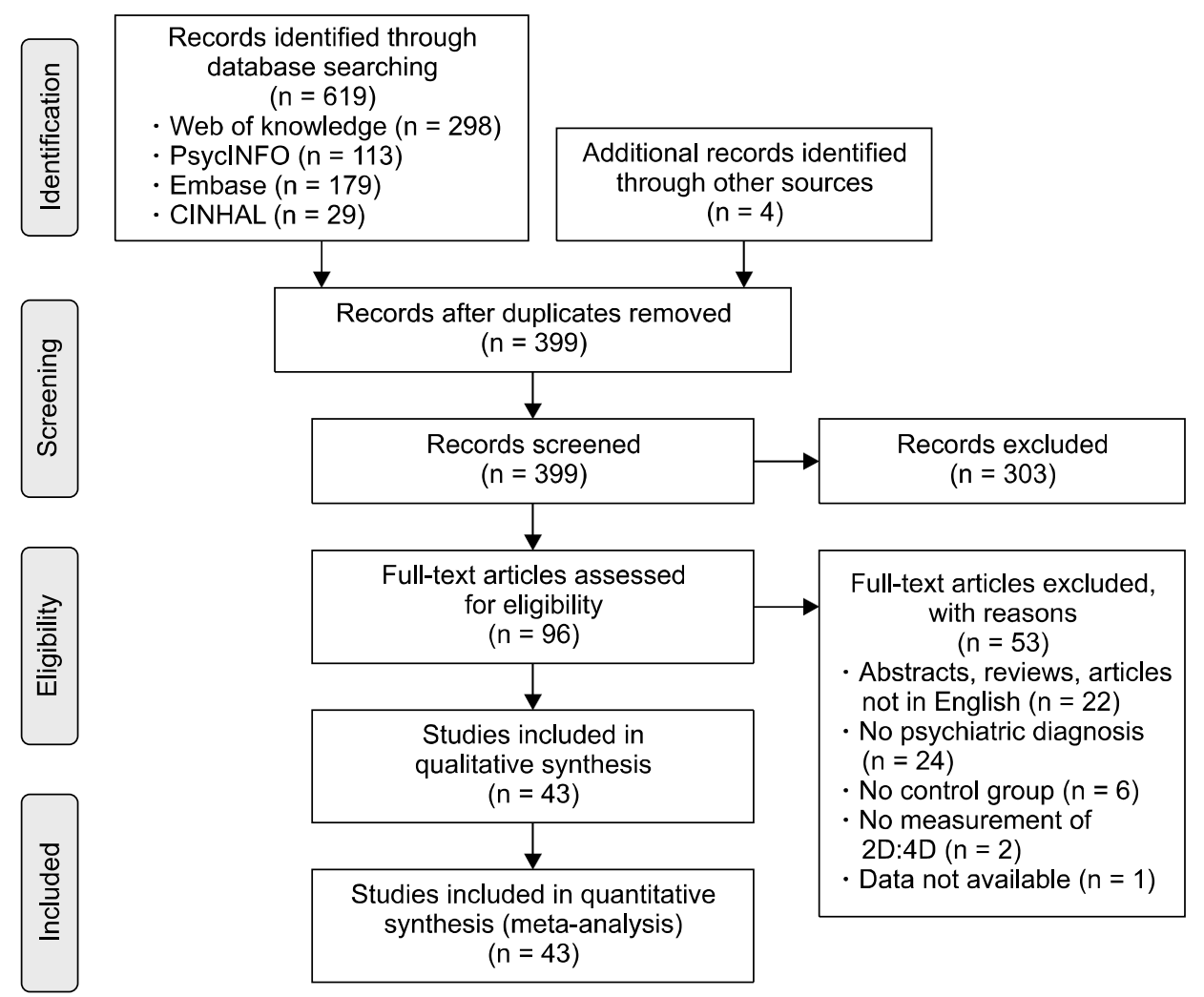

Fig. 1. PRISMA Flow Chart of the study selection process. 2D:4D, Second-to-fourth Digit Ratio.

ies were conducted in Asia, specifically in Japan, Iran, Saudi Arabia, and Thailand. Finally, three studies were conducted in the United States. Participants were children in all the studies involving patients with ADHD and ID. Moreover, five studies evaluated 2D:4D in adults with ASD [32-36], and two studies included mixed samples of children and adults with ASD $[37,38]$. Four papers included only males [36,39-41], and in two articles [31,42], the proportion of males represented almost the entirety of the sample. Five studies evaluated the 2D:4D only in the right hand, twelve studies in both hands (left and right). In one paper the mean between the 2D:4D of left and right hands was calculated, and in two studies it was unclear which hand was measured. Measurement of 2D:4D was mostly direct (14 studies).

Characteristics of the included studies about 2D:4D ratio in patients with neurodevelopmental disorders are reported in Table 1 [31-51].

\section{Schizophrenia}

Eight studies measured 2D:4D in patients with schizophrenia and controls. Half of the studies were conducted in Asia, and particularly two in India $[52,53]$, one in
China [54], and one in Singapore [55]. Moreover, two studies were conducted in Turkey [56,57], one in Spain [58], and one in Germany [22]. All participants were adults with mean ages ranging from 22 [57] to 47 [58]. Samples generally included both males and females, apart from Bolu et al. [57] that recruited only males. All papers have evaluated 2D:4D in both hands, apart from Collinson et al. [55] that has measured the ratio solely of the right hand. Measurements were always direct, except in two cases $[22,54]$. Characteristics of the included studies about $2 \mathrm{D}: 4 \mathrm{D}$ ratio in patients with schizophrenia are reported in Table 2.

\section{Addictions}

Two papers recruited individuals with alcohol dependence and were conducted in South Korea [59] and Germany [60]. Moreover, we included three studies involving participants with heroin dependence, which were conducted in Turkey [61,62] and Germany [63]. Participants were all adults, with mean ages ranging from 22.8 [61] to 51.2 [59]. Three studies included only men [59,61,62], while in the remaining two articles samples were mixed. Three papers measured 2D:4D ratio in both hands; one paper 


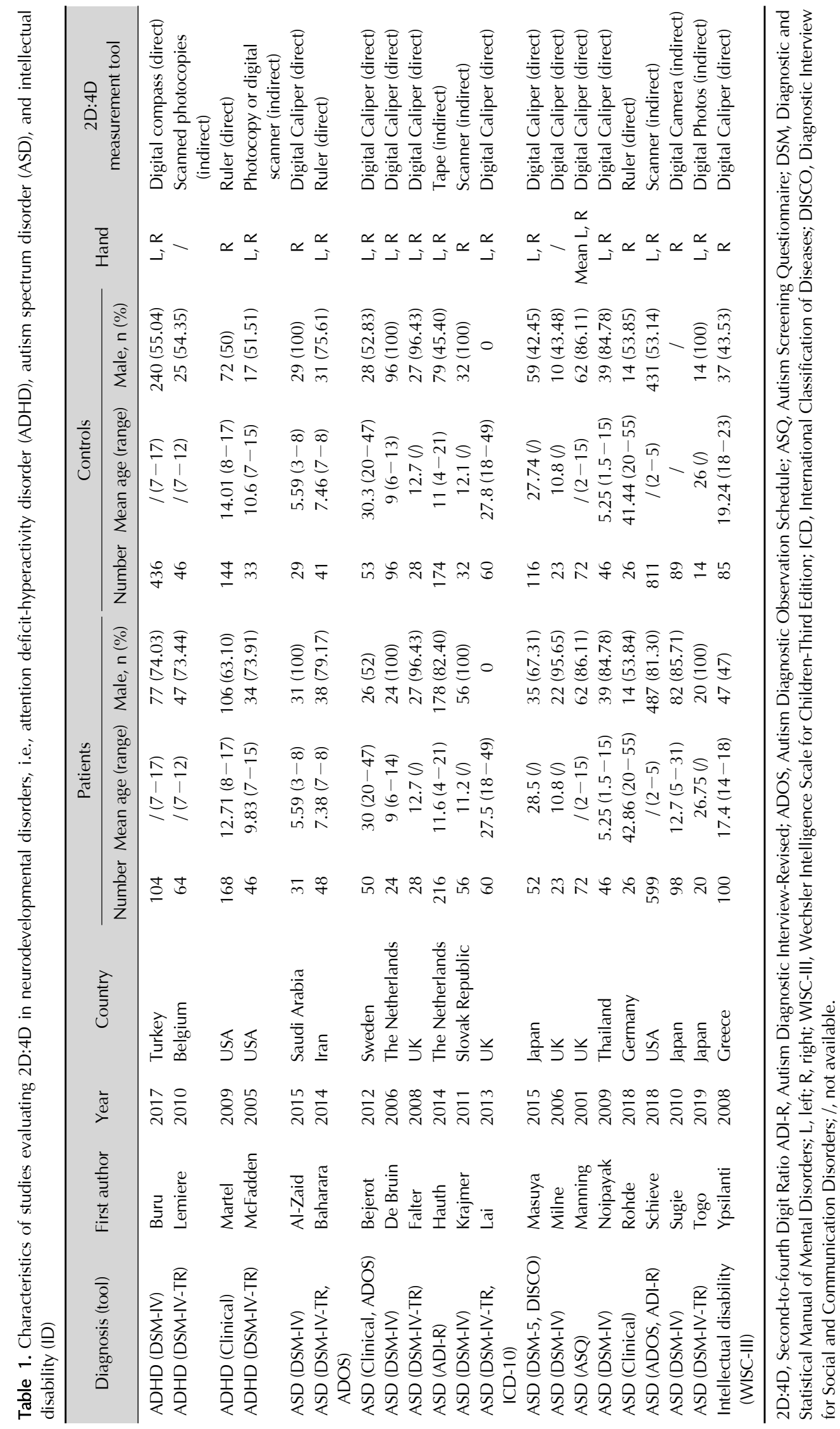



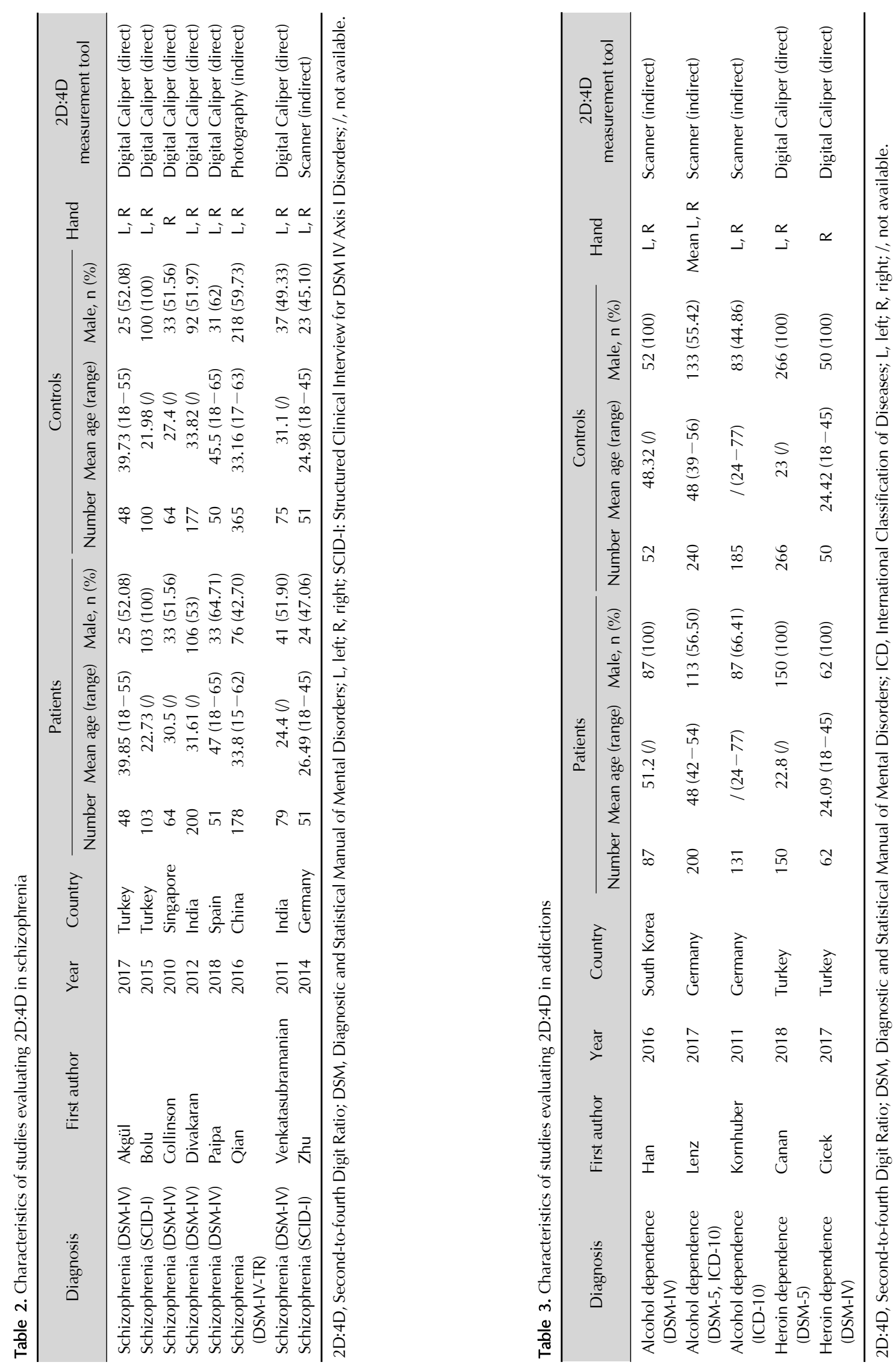

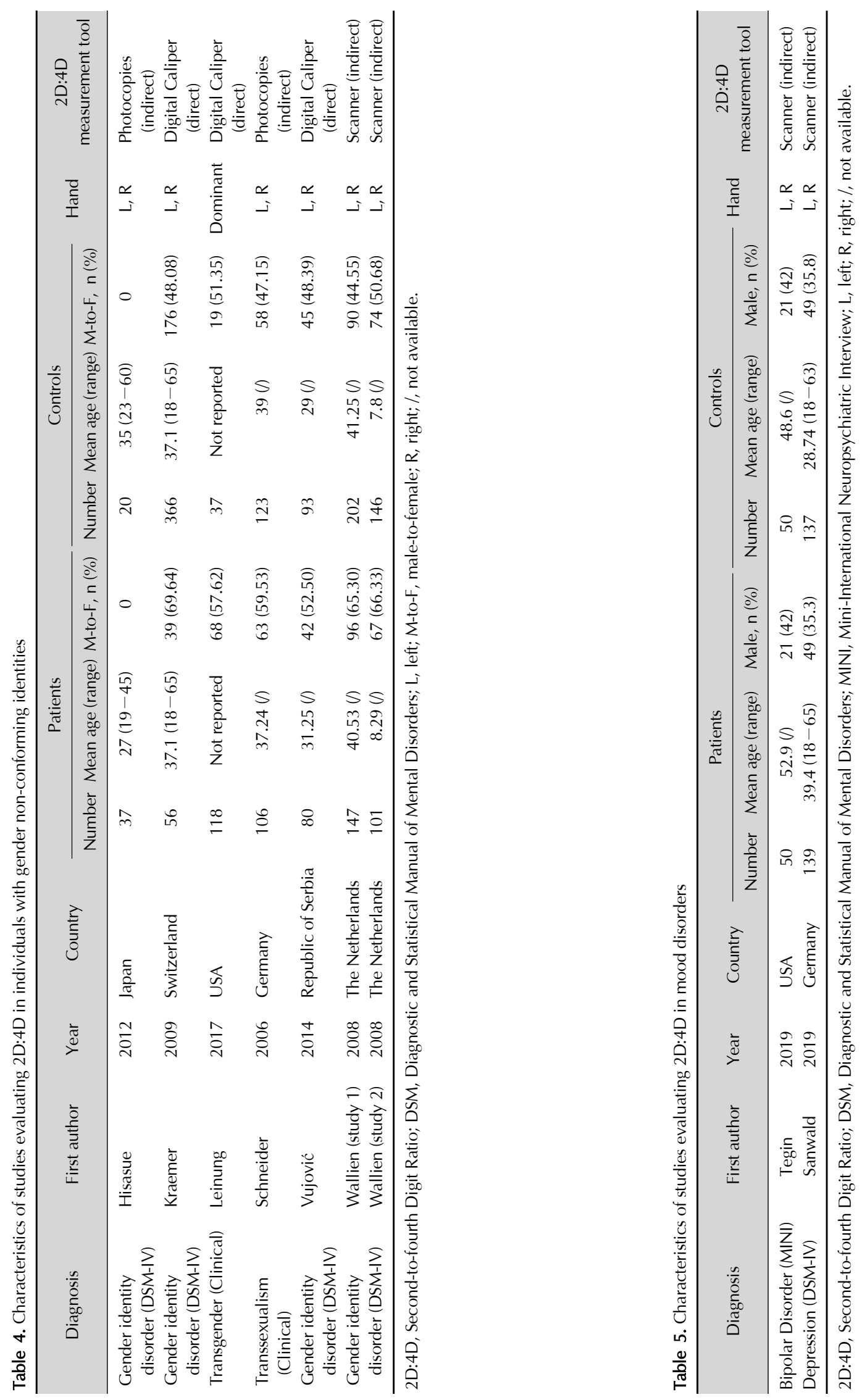
considered the average between the left and right hand [60] and one measured only right hand [62]. Measurements were indirect in three papers $[59,60,63]$, and direct in two articles [61,62]. See Table 3 for details regarding studies evaluating 2D:4D in addictions.

\section{Gender non-conforming identity}

Six papers (including seven studies) measured 2D:4D in people with gender nonconforming identity who had a psychiatric diagnosis or were followed by specialized clinics. Particularly, in four studies participants had a diagnosis of gender identity disorder, in one study a diagnosis of transsexualism, whereas they were defined as transgender in one paper. Studies were conducted mainly in Europe, specifically one in The Netherlands (including two studies) [64], one in Germany [65], one in the Republic of Serbia [66], and one in Switzerland [67]. Moreover, one study was conducted in Japan [68] and one in the United States [69]. One study involved children [64]; all the other studies recruited adults, with the exception of Leinung and $\mathrm{Wu}$ [69], where the age of participants was not reported. All studies evaluated 2D:4D in both hands; Leinung and Wu [69] have measured the ratio only in the dominant hand. Measurements were conducted directly in half of the studies, and indirectly in the remaining articles. Study characteristics are reported in Table 4 [66].

\section{Mood disorders}

One paper [70] recruited patients with major depression in Germany, and another study recruited individuals affected by bipolar disorder [71] in the United States. All participants were adults and mainly women. In the two studies regarding mood disorders, 2D:4D was measured in both hands and using indirect measurement tools. Details regarding the study characteristics are reported in Table 5.

\section{Meta-analyses of the Included Studies}

\section{D:4D ratio in all psychiatric disorders}

To evaluate the global differences of 2D:4D in psychiatric disorders, we conducted four main meta-analyses. In the first one, we pooled the data of all 43 studies, finding that psychiatric patients had significantly lower 2D:4D than healthy controls $(n=43$, overall sample $=9,484, M D=$ $-0.0056,95 \%$ confidence interval $[\mathrm{Cl}]$ from -0.0093 to
$-0.002, \mathrm{I}^{2}=74 \%$ ). The forest plot is presented in Figure 2 and the funnel plot in Figure 3.

Then, data extracted from included studies were pooled by hand, gender, and age. No differences were found between left and right hand in any psychiatric disorder $\left(\chi^{2}=\right.$ $0.85, \mathrm{df}=1, p=0.36$ ). However, considering each subgroup independently, it could be observed that the 2D:4D in the right hand showed significant lower 2D:4D in psychiatric patients than controls; conversely, no differences between psychiatric patients and controls were detected in the left hand. Moreover, no significant differences were detected between males and females $\left(\chi^{2}=0.44, \mathrm{df}=1, p=\right.$ $0.51)$, even if both groups showed significantly lower 2D:4D in psychiatric patients than controls. Finally, dividing the studies by age, it could be observed that both adults and children showed significantly lower 2D:4D ratio in psychiatric patients than controls, with no significant differences between the two groups $\left(\chi^{2}=0.77, \mathrm{df}=1, p=\right.$ 0.38). The forest plots are presented in the Supplementary Materials, Appendix 2 (available online) [27].

\section{D:4D ratio in autism spectrum disorder}

The analyses of the 2D:4D ratio in ASD, with data pooled by hand and gender, showed a statistically significant difference between patients and controls $(n=16$, overall sample $=2,981, \mathrm{MD}=-0.006,95 \% \mathrm{Cl}$ from 0.0119 to -0.0001$)$. Heterogeneity was moderate $\left(\mathrm{I}^{2}=\right.$ $53 \%)$. The results of the meta-analysis are presented in Figure 4A.

Subgroup analyses with studies divided by hand and gender did not detect any significant difference between ASD patients and controls. The forest plots of subgroup analyses are presented in the Supplementary Materials, Appendix 3 (available online) [27].

\section{D:4D ratio in attention deficit-hyperactivity disorder}

The meta-analysis of 2D:4D ratio in ADHD showed a statistically significant difference between patients and controls $(n=4$, overall sample $=1,128, M D=-0.0124$, $95 \% \mathrm{Cl}$ from -0.0188 to -0.0059$)$. Heterogeneity was low $\left(\mathrm{I}^{2}=0 \%\right)$. The results of the meta-analysis are presented in Figure 4B.

Subgroup analyses revealed significant differences in the right hand of both males $(n=3$, overall sample $=526$, $\mathrm{MD}=-0.0198,95 \% \mathrm{Cl}$ from -0.036 to $-0.0036, \mathrm{I}^{2}=65 \%$ ) and females $(n=3$, overall sample $=382, M D=-0.0245$, 


\section{Study}

Al-Zaid 2015

Milne 2006

Hisasue 2012

Manning 2001

Noipayak 2009

Sugie 2010

De Bruin 2006

Martel 2009

Cicek 2017

Kornhuber 2011

Han 2016

Venkatasubramanian 2011

Krajmer 2011

Rohde 2018

Baharara 2014

Buru 2017

McFadden 2005

Bolu 2015

Canan 2018

Paipa 2018

Wallien (study 1) 2008

Divakaran 2012

Lenz 2017

Zhu 2014

Leinung 2017

Vujović 2014

Lai 2013

Schieve 2018

Wallien (study 2) 2008

Sanwald 2019

Masuya 2015

Falter 2008

Lemiere 2010

Schneider 2006

Hauth 2014

Kraemer 2009

Tegin 2019

Ypsilanti 2008

Akgul 2017

Collinson 2010

Togo 2019

Bejerot 2012

Qian 2016

\section{Psychiatric disorders}

Total Mean SD

$\begin{array}{llll}31 & 0.9100 & 0.1106\end{array}$

$\begin{array}{lll}23 & 0.9510 & 0.1124\end{array}$

$\begin{array}{lll}37 & 0.9545 & 0.0309\end{array}$

$\begin{array}{lll}72 & 0.9500 & 0.0400\end{array}$

$\begin{array}{llll}46 & 0.9900 & 0.0617\end{array}$

$\begin{array}{lll}28 & 0.9320 & 0.0797\end{array}$

$\begin{array}{lll}24 & 0.9365 & 0.0327\end{array}$

$\begin{array}{lll}168 & 0.9448 & 0.1539\end{array}$

$\begin{array}{llll}62 & 0.9600 & 0.1106\end{array}$

$\begin{array}{lll}131 & 0.9560 & 0.0312\end{array}$

$\begin{array}{llll}87 & 0.9380 & 0.0251\end{array}$

$\begin{array}{llll}79 & 0.9726 & 0.0435\end{array}$

$\begin{array}{lll}56 & 0.9340 & 0.1048\end{array}$

$\begin{array}{llll}34 & 1.0000 & 0.1212\end{array}$

$\begin{array}{llll}48 & 0.9730 & 0.0498\end{array}$

$\begin{array}{lll}104 & 0.9789 & 0.0329\end{array}$

$\begin{array}{llll}23 & 0.9526 & 0.0290\end{array}$

$\begin{array}{lll}103 & 0.9705 & 0.0361\end{array}$

$\begin{array}{lll}150 & 0.9800 & 0.0285\end{array}$

$\begin{array}{llll}51 & 0.9818 & 0.1383\end{array}$

$\begin{array}{lll}147 & 0.9614 & 0.0351\end{array}$

$\begin{array}{lll}198 & 0.9624 & 0.0404\end{array}$

$\begin{array}{lll}200 & 0.9621 & 0.0320\end{array}$

$\begin{array}{lll}51 & 0.9671 & 0.0299\end{array}$

$\begin{array}{llll}118 & 0.9801 & 0.1071\end{array}$

$\begin{array}{llll}80 & 0.9277 & 0.0852\end{array}$

$\begin{array}{llll}30 & 0.9690 & 0.0274\end{array}$

$\begin{array}{lll}599 & 0.9429 & 0.0290\end{array}$

$\begin{array}{lll}101 & 0.9656 & 0.0454\end{array}$

$\begin{array}{lll}115 & 0.9775 & 0.0316\end{array}$

$\begin{array}{llll}52 & 0.9497 & 0.0338\end{array}$

$\begin{array}{llll}28 & 0.9715 & 0.0342\end{array}$

$\begin{array}{lll}128 & 0.9530 & 0.1187\end{array}$

$\begin{array}{lll}106 & 0.9634 & 0.0402\end{array}$

$\begin{array}{llll}216 & 0.9734 & 0.0360\end{array}$

$\begin{array}{lll}56 & 0.9667 & 0.0293\end{array}$

$\begin{array}{llll}50 & 0.9670 & 0.0280\end{array}$

$\begin{array}{llll}100 & 0.9805 & 0.0374\end{array}$

$\begin{array}{llll}48 & 1.0093 & 0.0379\end{array}$

$\begin{array}{llll}64 & 0.9824 & 0.1197\end{array}$

$\begin{array}{lll}20 & 0.9580 & 0.1239\end{array}$

$\begin{array}{lll}50 & 0.9826 & 0.0366\end{array}$

$\begin{array}{lll}178 & 0.9705 & 0.0377\end{array}$

\section{Controls}

Total Mean SD

$\begin{array}{llll}29 & 0.9600 & 0.1106\end{array}$

$\begin{array}{llll}23 & 0.9920 & 0.1179\end{array}$

$\begin{array}{llll}20 & 0.9890 & 0.0356\end{array}$

$\begin{array}{llll}72 & 0.9800 & 0.1179\end{array}$

$\begin{array}{llll}46 & 1.0150 & 0.0332\end{array}$

$\begin{array}{llll}30 & 0.9552 & 0.0757\end{array}$

$\begin{array}{llll}96 & 0.9570 & 0.0323\end{array}$

$\begin{array}{llll}144 & 0.9650 & 0.1652\end{array}$

$\begin{array}{llll}50 & 0.9800 & 0.1436\end{array}$

$\begin{array}{llll}185 & 0.9759 & 0.0293\end{array}$

$\begin{array}{llll}52 & 0.9570 & 0.0285\end{array}$

$\begin{array}{llll}75 & 0.9901 & 0.0392\end{array}$

$\begin{array}{llll}32 & 0.9510 & 0.1087\end{array}$

$\begin{array}{llll}26 & 1.0154 & 0.1204\end{array}$

$\begin{array}{llll}41 & 0.9880 & 0.0351\end{array}$

$\begin{array}{llll}436 & 0.9917 & 0.0367\end{array}$

$\begin{array}{llll}33 & 0.9645 & 0.0343\end{array}$

$\begin{array}{lll}100 & 0.9815 & 0.0370\end{array}$

$\begin{array}{llll}266 & 0.9900 & 0.0379\end{array}$

$\begin{array}{llll}50 & 0.9911 & 0.1281\end{array}$

$\begin{array}{llll}202 & 0.9700 & 0.0362\end{array}$

$\begin{array}{llll}175 & 0.9699 & 0.0289\end{array}$

$\begin{array}{llll}240 & 0.9687 & 0.0314\end{array}$

$\begin{array}{llll}51 & 0.9726 & 0.0365\end{array}$

$\begin{array}{llll}37 & 0.9846 & 0.1089\end{array}$

$\begin{array}{llll}186 & 0.9322 & 0.0538\end{array}$

$\begin{array}{llll}30 & 0.9735 & 0.0275\end{array}$

8110.94640 .0309

$\begin{array}{llll}146 & 0.9671 & 0.0370\end{array}$

$\begin{array}{llll}127 & 0.9788 & 0.0283\end{array}$

$\begin{array}{lll}116 & 0.9508 & 0.0285\end{array}$

$\begin{array}{llll}31 & 0.9715 & 0.0312\end{array}$

$\begin{array}{llll}92 & 0.9510 & 0.1211\end{array}$

$\begin{array}{llll}123 & 0.9609 & 0.0315\end{array}$

$\begin{array}{lll}174 & 0.9697 & 0.0373\end{array}$

$\begin{array}{llll}366 & 0.9630 & 0.0330\end{array}$

$\begin{array}{llll}50 & 0.9580 & 0.0337\end{array}$

$\begin{array}{llll}85 & 0.9713 & 0.0265\end{array}$

$\begin{array}{lllll}48 & 0.9986 & 0.0299\end{array}$

$\begin{array}{llll}64 & 0.9686 & 0.1140\end{array}$

$\begin{array}{llll}14 & 0.9430 & 0.1207\end{array}$

$\begin{array}{llll}53 & 0.9674 & 0.0302\end{array}$

$\begin{array}{llll}365 & 0.9516 & 0.0349\end{array}$
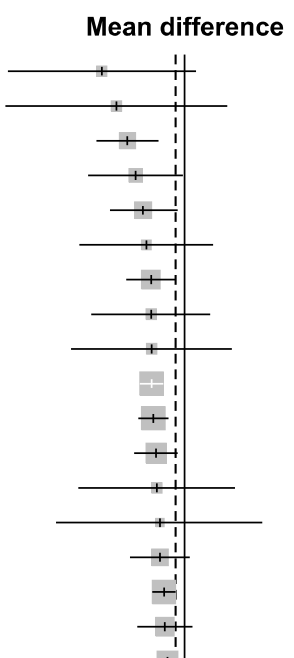

(1)

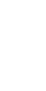

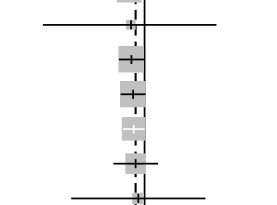

5,392

Random effects model $\quad 4,092$

$0<01$

Terogeneity: $l^{2}=74 \%[65 \% ; 81 \%], \tau^{2}<0.01$

Fig. 2. Meta-analysis of the 2D:4D ratio pooling all psychiatric disorders $(n=43)$.

2D:4D, Second-to-fourth Digit Ratio; SD, standard deviation; MD, mean difference; $\mathrm{Cl}$, confidence interval.

$95 \% \mathrm{Cl}$ from -0.0451 to $\left.-0.0039, \mathrm{I}^{2}=66 \%\right)$. No significant differences were found in the left hand, neither in males nor in females. The forest plots of the subgroup analyses plot are presented in the Supplementary Materials, Appendix 4 (available online) [27].
2D:4D ratio in intellectual disability

Only one study [48] evaluated 2D:4D ratio in ID, without detecting any significant difference. Forest plot is presented in Figure 4C [27].

\section{D:4D ratio in schizophrenia}

The meta-analysis of pooled data did not show any sig-

\begin{tabular}{lrr}
\multicolumn{1}{l}{0.0500} & {$[-0.1060 ; 0.0060]$} & $0.4 \%$ \\
-0.0410 & {$[-0.1076 ; 0.0256]$} & $0.3 \%$ \\
-0.0345 & {$[-0.0530 ;-0.0160]$} & $2.0 \%$ \\
-0.0300 & {$[-0.0588 ;-0.0012]$} & $1.2 \%$ \\
-0.0250 & {$[-0.0452 ;-0.0048]$} & $1.8 \%$ \\
-0.0232 & {$[-0.0633 ; 0.0169]$} & $0.7 \%$ \\
-0.0205 & {$[-0.0351 ;-0.0059]$} & $2.5 \%$ \\
-0.0202 & {$[-0.0559 ; 0.0154]$} & $0.8 \%$ \\
-0.0200 & {$[-0.0684 ; 0.0284]$} & $0.5 \%$ \\
-0.0199 & {$[-0.0267 ;-0.0131]$} & $3.7 \%$ \\
-0.0190 & {$[-0.0284 ;-0.0096]$} & $3.4 \%$ \\
-0.0175 & {$[-0.0306 ;-0.0045]$} & $2.8 \%$ \\
-0.0170 & {$[-0.0636 ; 0.0296]$} & $0.5 \%$ \\
-0.0154 & {$[-0.0770 ; 0.0463]$} & $0.3 \%$ \\
-0.0150 & {$[-0.0327 ; 0.0027]$} & $2.1 \%$ \\
-0.0128 & {$[-0.0200 ;-0.0057]$} & $3.7 \%$ \\
-0.0120 & {$[-0.0286 ; 0.0047]$} & $2.3 \%$ \\
-0.0110 & {$[-0.0211 ;-0.0009]$} & $3.2 \%$ \\
-0.0100 & {$[-0.0164 ;-0.0036]$} & $3.8 \%$ \\
-0.0093 & {$[-0.0613 ; 0.0426]$} & $0.4 \%$ \\
-0.0086 & {$[-0.0161 ;-0.0010]$} & $3.6 \%$ \\
-0.0075 & {$[-0.0145 ;-0.0004]$} & $3.7 \%$ \\
-0.0066 & {$[-0.0125 ;-0.0006]$} & $3.9 \%$ \\
-0.0055 & {$[-0.0184 ; 0.0075]$} & $2.8 \%$ \\
-0.0045 & {$[-0.0446 ; 0.0355]$} & $0.7 \%$ \\
-0.0045 & {$[-0.0247 ; 0.0157]$} & $1.8 \%$ \\
-0.0045 & {$[-0.0184 ; 0.0094]$} & $2.6 \%$ \\
-0.0035 & {$[-0.0067 ;-0.0004]$} & $4.2 \%$ \\
-0.0016 & {$[-0.0123 ; 0.0091]$} & $3.1 \%$ \\
-0.0012 & {$[-0.0088 ; 0.0063]$} & $3.6 \%$ \\
-0.0011 & {$[-0.0116 ; 0.0095]$} & $3.2 \%$ \\
0.0000 & {$[-0.0167 ; 0.0167]$} & $2.3 \%$ \\
0.0020 & {$[-0.0302 ; 0.0342]$} & $1.0 \%$ \\
0.0025 & {$[-0.0070 ; 0.0119]$} & $3.3 \%$ \\
0.0037 & {$[-0.0037 ; 0.0110]$} & $3.7 \%$ \\
0.0037 & {$[-0.0047 ; 0.0121]$} & $3.5 \%$ \\
0.0090 & {$[-0.0031 ; 0.0211]$} & $2.9 \%$ \\
0.0092 & {$[0.0000 ; 0.0185]$} & $3.4 \%$ \\
0.0107 & {$[-0.0030 ; 0.0243]$} & $2.7 \%$ \\
0.0137 & {$[-0.0268 ; 0.0542]$} & $0.7 \%$ \\
0.0150 & {$[-0.0683 ; 0.0983]$} & $0.2 \%$ \\
0.0152 & {$[0.0022 ; 0.0282]$} & $2.8 \%$ \\
0.0189 & {$[0.0123 ; 0.0255]$} & $3.8 \%$ \\
\hline & & \\
-0.0056 & {$[-0.0093 ;-0.0020]$} & $100.0 \%$ \\
\hline & & \\
\hline & &
\end{tabular}




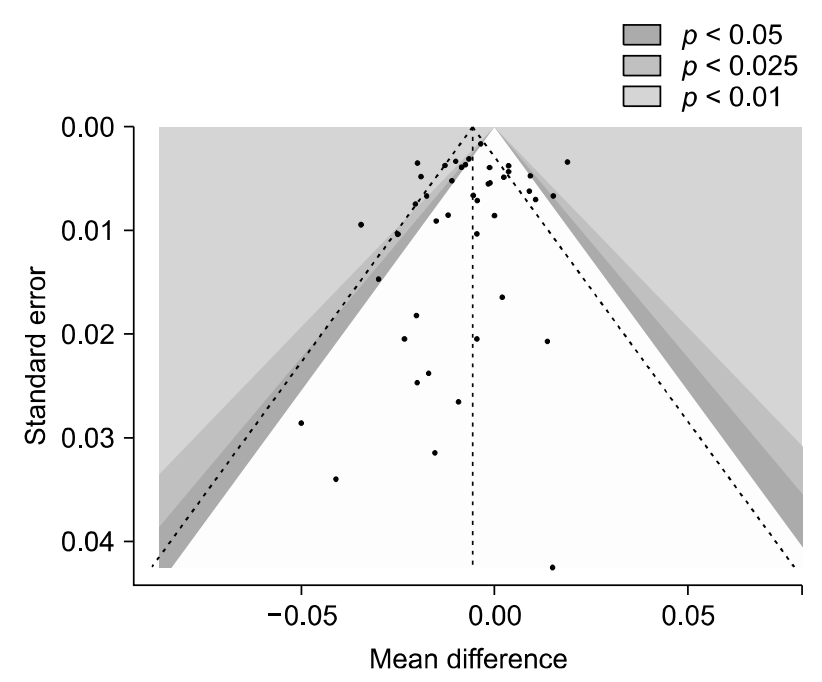

Fig. 3. Funnel plot of the included studies $(n=43)$.

nificant difference between patients with schizophrenia and other psychotic disorders and non-clinical controls $(\mathrm{n}=$ 8 , overall sample $=1,700, \mathrm{MD}=-0.0012,95 \% \mathrm{Cl}$ from -0.0129 to 0.0105$)$. Heterogeneity was high $\left(I^{2}=86 \%\right)$. The forest plot is presented in Figure 4D.

Subgroup analyses with data divided by gender and hand did not reveal any significant difference except for the right hand in males: in this group, the 2D:4D ratio was significantly higher in patients than controls $(n=6$, overall sample $=882, \mathrm{MD}=0.009,95 \% \mathrm{Cl}$ from 0.0004 to $0.0177, I^{2}=64 \%$ ). The subgroup analyses are presented in the Supplementary Materials, Appendix 5 (available online) [27].

\section{D:4D ratio in addictions}

Pooling data of patients affected by addictions, we did find a significant difference, as patients had a significantly lower 2D:4D than controls ( $\mathrm{n}=5$, overall sample $=1,423$, $\mathrm{MD}=-0.014,95 \% \mathrm{Cl}$ from -0.0199 to -0.0081$)$. Heterogeneity was moderate $\left(\mathrm{I}^{2}=50 \%\right)$. The forest plot is presented in Figure 4E.

The subgroup analyses revealed statistically significant differences in both the males right and left hands, while for females the difference between the patients and the control group was limited to the right hand. In all cases, the patients suffering from addictions had a smaller 2D:4D ratio than controls. The analyses are presented in the Supplementary Materials, Appendix 6 (available online) [27].

\section{D:4D ratio in gender non-conforming people}

No significant differences were found between individuals with gender non-conforming identities $(n=7$, overall sample $=1,725, \mathrm{MD}=-0.0051,95 \% \mathrm{Cl}$ from -0.0131 to 0.0028$)$. Heterogeneity was substantial $\left(I^{2}=65 \%\right)$. Forest plot is presented in Figure 4F.

Subgroup analyses did not detect any significant differences according to hand or biological sex (see Supplementary Materials, Appendix 7 [available online] [27]).

\section{$2 D: 4 D$ ratio in mood disorders}

We found no significant differences between patients with depression or bipolar disorder and healthy controls ( $\mathrm{n}=2$, overall sample $=342, \mathrm{MD}=0.0027,95 \% \mathrm{Cl}$ from -0.0071 to 0.0125$)$. Heterogeneity was moderate $\left(\mathrm{I}^{2}=\right.$ 49\%). Forest plot is presented in Figure 4G.

\section{Quality of the Included Studies}

The quality of the studies included in the systematic review and meta-analysis has been reported in Table 6 . Two studies were judged with a score of 4 out of 9 points $[41,42]$, four studies with 5 out of $9[49,55,65,66]$, ten studies with 6 out of 9 , four studies with 7 out of 9 and the the remaining papers with 8 or 9 stars. As concerns the study selection, we have found a relatively low risk of bias in diagnostic criteria: in fact, we included only studies in which participants had received a psychiatric diagnosis by a clinician. Only two studies were judged as having high risk: first, participants recruited by Manning et al. [50] were members of an autistic society and the diagnoses were confirmed only using the Autism Screening Questionnaire (ASQ), which is not intended as a diagnostic tool [72]; second, in Schneider et al. [65], transgenders were followed by a specific clinic for transition, thus we assumed that a clinical diagnosis had been performed, even if not explicitly reported in the paper. As for the remaining items of study selection, the most problematic criterion was the representativeness of cases, as in most studies the authors did not report consecutive recruitment of patients, thus raising concerns regarding potential selection biases. Ten studies did not match patients to controls according to socio-demographic variables, while in seven study only one variable was considered (age or gender). Regarding exposure, we did not find major biases, since the 2D:4D ratio was measured in cases and controls using the same methodology with direct or indirect measures. 
A Autism spectrum disorder (ASD)

\begin{tabular}{lrccccc} 
Study & \multicolumn{3}{c}{ ASD } & \multicolumn{3}{c}{ Controls } \\
Al-Zaid 2015 & 31 & 0.9100 & 0.1106 & 29 & 0.9600 & 0.1106 \\
Milne 2006 & 23 & 0.9510 & 0.1124 & 23 & 0.9920 & 0.1179 \\
Manning 2001 & 72 & 0.9500 & 0.0400 & 72 & 0.9800 & 0.1179 \\
Noipayak 2009 & 46 & 0.9900 & 0.0617 & 46 & 1.0150 & 0.0332 \\
Sugie 2010 & 28 & 0.9320 & 0.0797 & 30 & 0.9552 & 0.0757 \\
De Bruin 2006 & 24 & 0.9365 & 0.0327 & 96 & 0.9570 & 0.0323 \\
Krajmer 2011 & 56 & 0.9340 & 0.1048 & 32 & 0.9510 & 0.1087 \\
Rohde 2018 & 34 & 1.0000 & 0.1217 & 26 & 1.0154 & 0.1215 \\
Baharara 2014 & 48 & 0.9730 & 0.0498 & 41 & 0.9880 & 0.0351 \\
Lai 2013 & 30 & 0.9690 & 0.0274 & 30 & 0.9735 & 0.0275 \\
Schieve 2018 & 599 & 0.9429 & 0.0291 & 811 & 0.9464 & 0.0310 \\
Masuya 2015 & 52 & 0.9497 & 0.0338 & 116 & 0.9508 & 0.0285 \\
Falter 2008 & 28 & 0.9715 & 0.0342 & 31 & 0.9715 & 0.0312 \\
Hauth 2014 & 216 & 0.9734 & 0.0360 & 174 & 0.9697 & 0.0374 \\
Togo 2019 & 20 & 0.9580 & 0.1239 & 14 & 0.9430 & 0.1207 \\
Bejerot 2012 & 50 & 0.9826 & 0.0367 & 53 & 0.9674 & 0.0303
\end{tabular}

Random effects model $\quad 1,357$

1,624

Heterogeneity: $l^{2}=53 \%$ [17\%; 73\%], $\tau^{2}<0.0001, p<0.01$

Test for overall effect: $z=-1.99(p=0.0461)$

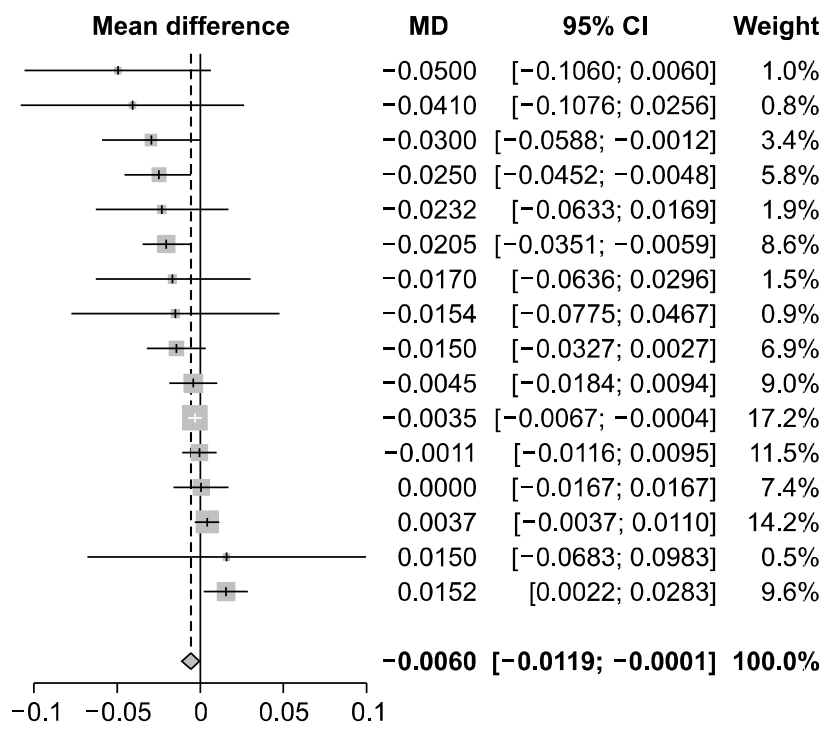

B Attention deficit-hyperactivity disorder (ADHD)

\begin{tabular}{lrrcrcc} 
Study & \multicolumn{3}{c}{ ADHD } & \multicolumn{3}{c}{ Controls } \\
Martel 2009 & 168 & 0.9448 & 0.1574 & 144 & 0.9650 & 0.1670 \\
Buru 2017 & 104 & 0.9789 & 0.0333 & 436 & 0.9917 & 0.0367 \\
McFadden 2005 & 23 & 0.9526 & 0.0291 & 33 & 0.9645 & 0.0342 \\
Lemiere 2010 & 128 & 0.9530 & 0.1187 & 92 & 0.9510 & 0.121
\end{tabular}

Random effects model $\mathbf{4 2 3}$

705

Heterogeneity: $I^{2}=0 \%[0 \% ; 52 \%], \tau^{2}=0, p=0.81$

Test for overall effect: $z=-3.77(p=0.0002)$

C Intellectual disability (ID)

Intellectual disability

Ypsilanti 2008 Total Mean SD Total Mean SD

Heterogeneity: $l^{2}=$ NA $\%$

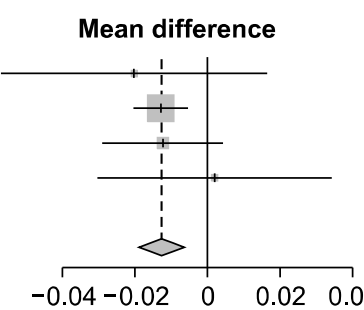

$\begin{array}{llll}-0.04-0.02 & 0 & 0.02 & 0.04\end{array}$

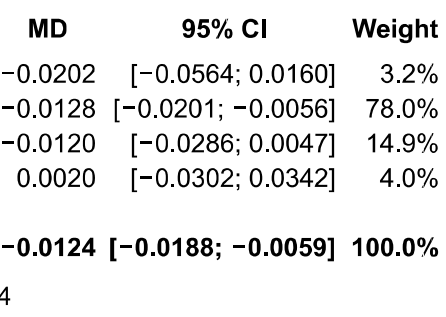

$-0.0202 \quad[-0.0564 ; 0.0160] \quad 3.2 \%$ $-0.0128[-0.0201 ;-0.0056] \quad 78.0 \%$ $-0.0120 \quad[-0.0286 ; 0.0047] \quad 14.9 \%$ $0.0124[-0.0188 ;-0.0059] 100.0 \%$

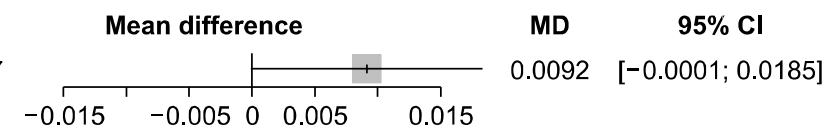

D Schizophrenia

\begin{tabular}{|c|c|c|c|c|c|c|c|c|c|c|}
\hline \multirow[b]{2}{*}{ Study } & \multicolumn{3}{|c|}{ Schizophrenia } & \multicolumn{3}{|c|}{ Controls } & \multirow[b]{2}{*}{ Mean difference } & \multirow[b]{2}{*}{ MD } & \multirow[b]{2}{*}{$95 \% \mathrm{Cl}$} & \multirow[b]{2}{*}{ Weight } \\
\hline & Total & Mean & SD & Total & Mean & SD & & & & \\
\hline Venkatasubramanian 2011 & 179 & 0.9726 & 0.0436 & 75 & 0.9901 & 0.0394 & -1 & -0.0175 & {$[-0.0306 ;-0.0044]$} & $14.2 \%$ \\
\hline Bolu 2015 & 103 & 0.9705 & 0.0361 & 100 & 0.9815 & 0.0370 & $\longrightarrow$ & -0.0110 & {$[-0.0211 ;-0.0009]$} & $15.4 \%$ \\
\hline Paipa 2018 & 51 & 0.9818 & 0.1388 & 50 & 0.9911 & 0.1282 & $\mp$ & -0.0093 & {$[-0.0614 ; 0.0428]$} & $3.9 \%$ \\
\hline Divakaran 2012 & 198 & 0.9624 & 0.0405 & 175 & 0.9699 & 0.0292 & + & -0.0075 & {$[-0.0146 ;-0.0004]$} & $16.3 \%$ \\
\hline Zhu 2014 & 51 & 0.9671 & 0.0299 & 51 & 0.9726 & 0.0365 & & -0.0055 & {$[-0.0184 ; 0.0075]$} & $14.3 \%$ \\
\hline Akgül 2017 & 48 & 1.0093 & 0.0379 & 48 & 0.9986 & 0.0299 & + & 0.0107 & {$[-0.0030 ; 0.0243]$} & $14.0 \%$ \\
\hline Collinson 2010 & 64 & 0.9824 & 0.1202 & 64 & 0.9686 & 0.1174 & $一$ & 0.0137 & {$[-0.0274 ; 0.0549]$} & $5.5 \%$ \\
\hline Qian 2016 & 178 & 0.9705 & 0.0378 & 365 & 0.9516 & 0.0349 & + & 0.0189 & {$[0.0123 ; 0.0255]$} & $16.4 \%$ \\
\hline Random effects model & 772 & & & 928 & & & & -0.0012 & {$[-0.0129 ; 0.0105]$} & $100.0 \%$ \\
\hline $\begin{array}{l}\text { Heterogeneity: } l^{2}=86 \% \text { [75 } \\
\text { Test for overall effect: } z=-\end{array}$ & $\begin{array}{l}5 \% ; 9 \\
-0.20\end{array}$ & $\begin{array}{l}2 \%], \tau^{2} \\
p=0\end{array}$ & 000 & $0<0.0$ & & & 0.02 & & & \\
\hline
\end{tabular}

Test for overall effect: $z=-0.20(p=0.8407)$

Fig. 4. Meta-analyses of the 2D:4D ratio in individual psychiatric disorders.

2D:4D, Second-to-fourth Digit Ratio; SD, standard deviation; MD, mean difference; $\mathrm{Cl}$, confidence interval. 


\section{E Addictions}

\begin{tabular}{|c|c|c|c|c|c|c|c|c|c|c|}
\hline \multirow[b]{2}{*}{ Study } & \multicolumn{3}{|c|}{ Addictions } & \multicolumn{3}{|c|}{ Controls } & \multirow{2}{*}{ Mean difference } & \multirow{2}{*}{ MD } & \multirow{2}{*}{$95 \% \mathrm{Cl}$} & \multirow[b]{2}{*}{ Weight } \\
\hline & Total & Mean & SD & Total & Mean & SD & & & & \\
\hline Cicek 2017 & 62 & 0.9600 & 0.1106 & 50 & 0.9800 & 0.1436 & $\begin{array}{c}1 \\
1\end{array}$ & -0.0200 & {$[-0.0684 ; 0.0284]$} & $1.4 \%$ \\
\hline Kornhuber 2011 & 131 & 0.9560 & 0.0311 & 185 & 0.9759 & 0.0293 & +1 & -0.0199 & {$[-0.0267 ;-0.0131]$} & $27.6 \%$ \\
\hline Han 2016 & 87 & 0.9380 & 0.0251 & 52 & 0.9570 & 0.0285 & +4 & -0.0190 & {$[-0.0284 ;-0.0096]$} & $20.8 \%$ \\
\hline Canan 2018 & 150 & 0.9800 & 0.0285 & 266 & 0.9900 & 0.0379 & + & -0.0100 & {$[-0.0164 ;-0.0036]$} & $28.6 \%$ \\
\hline Lenz 2017 & 200 & 0.9621 & 0.0544 & 240 & 0.9687 & 0.0395 & $1+$ & -0.0066 & {$[-0.0156 ; 0.0025]$} & $21.5 \%$ \\
\hline Random effects model & 630 & & & 793 & & & $\Delta$ & -0.0140 & {$[-0.0199 ;-0.0081]$} & $100.0 \%$ \\
\hline $\begin{array}{l}\text { Heterogeneity: } P^{2}=50 \%[0 \\
\text { Test for overall effect: } z=\end{array}$ & $\begin{array}{l}\% ; 82 \\
4.64\end{array}$ & 0 & & $=0.09$ & & & $\begin{array}{lll}-0.02 & 0 & 0.0\end{array}$ & & & \\
\hline
\end{tabular}

F Gender non-conforming identity

\begin{tabular}{|c|c|c|c|c|c|c|c|c|c|c|}
\hline \multirow{3}{*}{$\begin{array}{l}\text { Study } \\
\text { Hisasue } 2012\end{array}$} & \multicolumn{3}{|c|}{ Gender nonconformity } & \multicolumn{3}{|c|}{ Controls } & \multirow[b]{2}{*}{ ference } & \multirow[b]{2}{*}{ MD } & \multirow[b]{2}{*}{$95 \% \mathrm{Cl}$} & \multirow[b]{2}{*}{ Weight } \\
\hline & Total & Mean & & Total & Mean & SD & & & & \\
\hline & 37 & 0.9545 & 0.0309 & 20 & 0.9890 & 0.0356 & + & -0.0345 & {$[-0.0530 ;-0.0160]$} & $10.7 \%$ \\
\hline Wallien (study 1) 2008 & 147 & 0.9614 & 0.0356 & 202 & 0.9700 & 0.0360 & & -0.0086 & {$[-0.0162 ;-0.0010]$} & $20.8 \%$ \\
\hline Leinung 2017 & 118 & 0.9801 & 0.1073 & 37 & 0.9846 & 0.1150 & & -0.0045 & {$[-0.0463 ; 0.0373]$} & $3.2 \%$ \\
\hline Vujović 2014 & 80 & 0.9277 & 0.0892 & 186 & 0.9322 & 0.0548 & & -0.0045 & {$[-0.0256 ; 0.0166]$} & $9.1 \%$ \\
\hline Wallien (study 2) 2008 & 101 & 0.9656 & 0.0454 & 146 & 0.9671 & 0.0370 & & -0.0016 & {$[-0.0123 ; 0.0091]$} & $17.5 \%$ \\
\hline Schneider 2006 & 106 & 0.9634 & 0.0403 & 123 & 0.9609 & 0.0315 & & 0.0025 & {$[-0.0070 ; 0.0120]$} & $18.8 \%$ \\
\hline Kraemer 2009 & 56 & 0.9667 & 0.0295 & 366 & 0.9630 & 0.0329 & & 0.0037 & {$[-0.0048 ; 0.0121]$} & $19.9 \%$ \\
\hline andom effe & 645 & & & 1,080 & & & & -0.0051 & {$[-0.0131 ; 0.0028]$} & $100.0 \%$ \\
\hline $\begin{array}{l}\text { leterogeneity: } l^{2}=65 \% \text { [ } \\
\text { est for overall effect: } z=\end{array}$ & $\begin{array}{l}{[20 \% ; 84} \\
=-1.26\end{array}$ & $p=0.20$ & 67) & & & & 0 & 04 & & \\
\hline
\end{tabular}

G Mood disorders

\begin{tabular}{|c|c|c|c|c|c|c|c|c|c|c|}
\hline \multirow[b]{2}{*}{ Study } & \multicolumn{3}{|c|}{ Mood disorders } & \multicolumn{3}{|c|}{ Controls } & \multirow[b]{2}{*}{ Mean difference } & \multirow[b]{2}{*}{ MD } & \multirow[b]{2}{*}{$95 \% \mathrm{Cl}$} & \multirow[b]{2}{*}{ Weight } \\
\hline & Total & Mean & SD & Total & Mean & SD & & & & \\
\hline Sanwaid 2019 & 115 & 0.9775 & 0.0316 & 127 & 0.9788 & 0.0283 & 1 & -0.0012 & {$[-0.0088 ; 0.0063]$} & $61.1 \%$ \\
\hline Tegin 2019 & 50 & 0.9670 & 0.0280 & 50 & 0.9580 & 0.0337 & + & 0.0090 & {$[-0.0031 ; 0.0211]$} & $38.9 \%$ \\
\hline andom effects & 165 & & & 177 & & & 1. & 0.0027 & {$[-0.0071 ; 0.0125]$} & $100.0 \%$ \\
\hline eterogeneity: $l^{2}=49 \%$, & $<0.0$ & $001, p$ & & & & & 0.01 & 0.02 & & \\
\hline
\end{tabular}

Fig. 4. Continued.

However, in five studies $[35,41,42,51,65]$ concerns were raised because of missing data.

\section{DISCUSSION}

The present meta-analysis aimed to evaluate the differences in 2D:4D ratio between psychiatric patients and controls, and thus to explore its potential usefulness as a clinical biomarker for psychiatric disorders. The first and main finding of our meta-analysis is that the $2 \mathrm{D}: 4 \mathrm{D}$ ratio is significantly lower in patients than controls, indicating exposure to higher levels of prenatal testosterone in individuals with psychiatric disorder. The effect seemed more pronounced in males than females, in the right than the left hand, and in children than adults, even if be- tween-groups differences were not statistically significant. Our finding is important because, on one hand, it may propose 2D:4D as a potential biomarker for psychiatric disorders in general; on the other hand, it highlights the role of prenatal exposure to hormones, specifically testosterone, in the etiopathogenesis of psychiatric disorders. Interestingly, prenatal exposure to androgens may explain the different sex ratios encountered in several conditions (e.g., schizophrenia, ASD, addictions).

As shown by the number of studies included in our meta-analysis, the literature has extensively evaluated the 2D:4D in ASD for which we have included 16 case-control studies. Nevertheless, the effective measurement of sex steroid levels in the amniotic fluid with a prospective follow-up has been performed by a few researchers. 


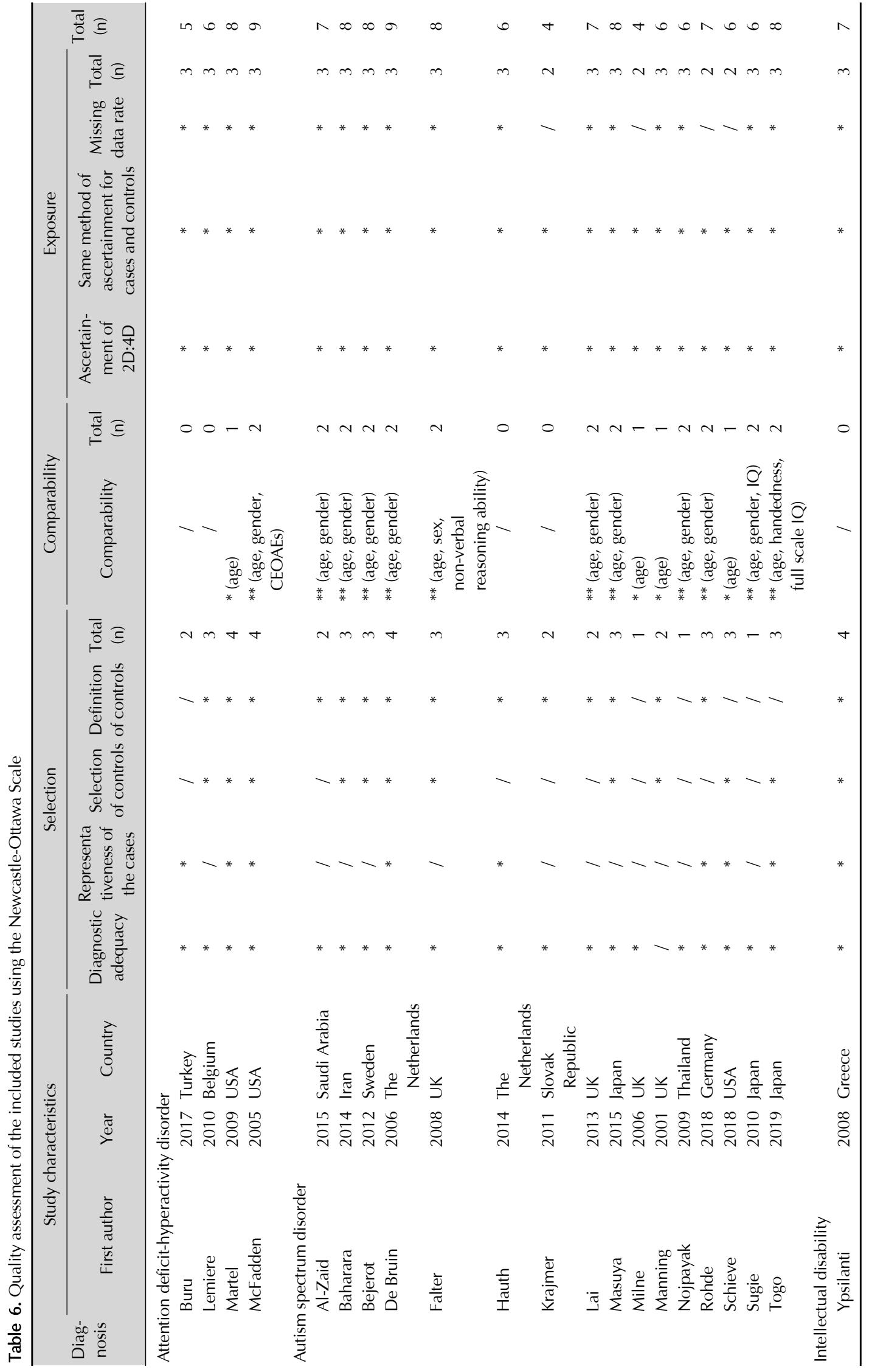




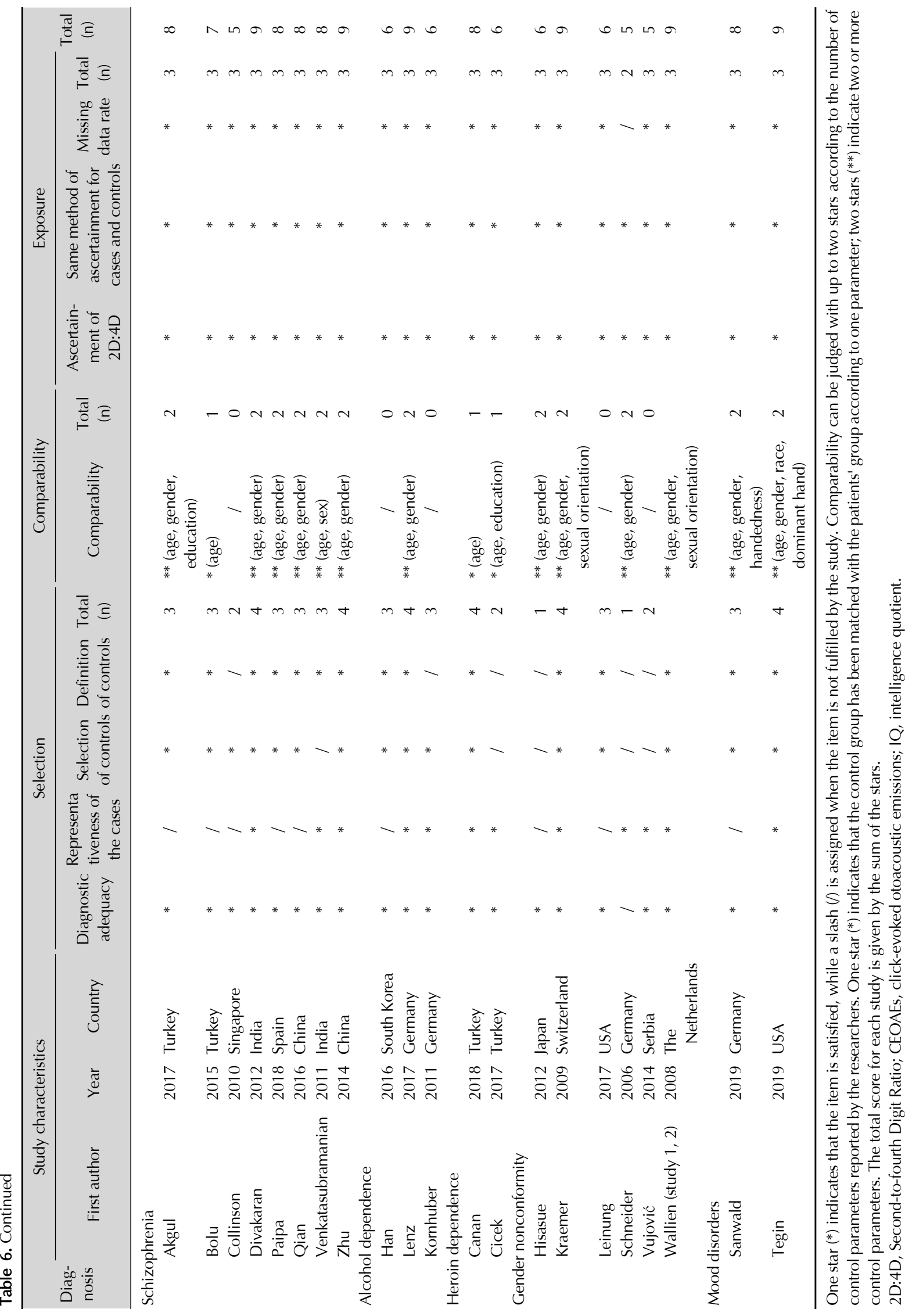


Auyeung et al. [73] positively correlated fetal testosterone levels with autism-related behaviors at $18-24$ months and at 6-9 years [74]. Elevated fetal steroidogenic activity during the prenatal masculinization window in the amniotic fluid of autistic boys was confirmed by subsequent research [75]. On the contrary, Kung et al. [76] recently found no relationship between prenatal androgen exposure and autistic traits in typically developed children nor in young children with congenital adrenal hyperplasia. Of note, 2D:4D has been negatively associated with empathy [77], which is typically lower in people with ASD [78]; conversely, it seems positively correlated with systemizing traits [79], which are more pronounced in autistic individuals [80]. In 2002, Baron-Cohen developed the so-called theory of the "extreme male brain”. This theory assumes that women tend to have more social intelligence (i.e., empathizing ability), whereas men tend to excel at following rules and recognizing patterns (i.e., systemizing ability). The "male brain" is typical of individuals in whom systemizing is significantly better than empathizing, while the "female brain" defines the opposite cognitive profile. Using these definitions, ASD could be considered as an expression of the "extreme male brain" [81]. The potential role of fetal testosterone in the onset of ASD is further supported by the link found between autism and maternal polycystic ovarian syndrome, a condition associated with androgenic excess [82]. Moreover, both autistic women and their mothers have elevated rates of steroid-related cancers, such as breast and ovarian cancer [83]. In summary, our findings reflect previous literature: subjects with ASD have significantly lower 2D:4D than controls, suggesting higher levels of fetal testosterone exposure.

Contrary to previous studies [84], our results did not support the notion that patients with schizophrenia would be exposed to lower levels of prenatal testosterone. In fact, it has been hypothesized that schizophrenia, in opposition with ASD, could reflect the "extreme female brain”, with higher empathizing and lower systemizing abilities [81]. However, as underlined by other researchers, this theory might be erroneously based on the presumption that "hyperdeveloped theory-of-mind skills" in psychotic patients "would be accurate and adaptive, rather than pathological" [85]. Indeed, our findings did not confirm the theory of the "extreme female brain", as 2D:4D did not significantly differ between patients with schizo- phrenia and controls, thus suggesting no differences in empathizing and/or systemizing traits, neither in prenatal exposure to sex hormones. In fact, a significant difference was found only in the right hand of males with schizophrenia (MD = 0.009).

The evidence on addictions was quite robust, as 2D:4D resulted significantly lower in patients than healthy controls $(\mathrm{MD}=-0.014)$, indicating exposure to higher levels of prenatal testosterone. Even if no specific studies have evaluated the levels of sex steroids in the amniotic fluid in people with addictions - due to the obvious difficulties in following up the subjects for many years-some studies have linked several typical features of individuals with substance misuse to the digit ratio. For instance, it has been shown that 2D:4D is negatively correlated with risk-taking $[18,86]$ and sensation-seeking $[87,88]$. Such features have been in turn linked to a higher vulnerability to addictions [89]. 2D:4D appears also negatively correlated with aggression [90] and impulsivity [91], which are in turn connected to the use of illicit substances, particularly alcohol and heroin [92], such as those used by the groups of patients included in our meta-analysis. Other authors [93] have argued an association between 2D:4D and externalizing behavioral symptoms in young boys: it is well-known that conduct disturbances confer an increased risk for substance abuse later in life [94]. Notably, this negative association between 2D:4D and externalizing behaviors may partially explain also the significant difference found between children with ADHD and non-clinical controls $(\mathrm{MD}=-0.0124)$.

Our meta-analyses did not retrieve any significant differences between people with non-conforming gender identities, mood disorders and ID, and non-clinical controls. The case of gender identity might seem surprising since in the imagination sex hormones are strictly connected to gender expression. However, it has been reported that gender identity is not exclusively related to prenatal exposure of androgens [95,96], but appears to be strongly influenced by genetic and social factors, with adolescence being a key period for the development of non-conforming identities $[97,98]$. As far as concern ID and mood disorders, it is worth noting that we have retrieved only one and two studies, respectively, and thus it is too premature to drive to any conclusion.

To our knowledge, this is the most up-to-date and comprehensive meta-analysis examining the 2D:4D ratio in 
psychiatry. However, some limitations should be discussed. First, we have included only papers in which psychiatric diagnoses were confirmed by clinicians or valid international diagnostic criteria. Therefore, we have excluded papers reporting analyses about 2D:4D in self-diagnosed individuals, or individuals which were classified as having a disorder only according to self-reported questionnaires $[99,100]$. Also, we excluded papers about new addictions, such as videogames or computer addiction, which have been instead considered in a previous meta-analysis [101]. A second major limitation is related to the different types of measurement used by the authors included in the studies. In fact, some authors have suggested that indirect 2D:4D measurements (such as in many of the studies included in the present review) may overestimate the length of the ring finger thereby distorting the 2D:4D ratio [16]. Another limitation, directly related to the meta-analytic approach, is the presence of clinical heterogeneity which could not be controlled as for statistical heterogeneity. Even if we tried to reduce clinical heterogeneity by selecting patients with standardized diagnoses, we could not account for the presence of individual or genetic differences, as well as for the influence of environmental factors. Finally, the number of studies included in the meta-analyses were generally small.

In conclusion, our results are promising and highlight the importance of prenatal hormonal factors in the etiopathogenesis of some psychiatric disorders. However, they need to be cautiously interpreted as the measurement of 2D:4D ratio cannot prescind from a complex and exhaustive assessment process. It is important to consider, in fact, that a number of other physiological and pathological conditions linked to the prenatal exposure to sex hormones may influence the length of digit ratio, thus representing potential confounders. The absence of a definite cut-off also represents a limitation for the clinical application of 2D:4D. Future research should investigate more in-depth the relationships between 2D:4D and psychiatric disorders, focusing on other conditions characterized by traits that seem to be linked to lower or higher digit ratio, such as borderline and antisocial personality disorders, eating disorders, or disruptive mood dysregulation disorder.

\section{SUPPLEMENTARY MATERIALS}

Supplementary data is available online (https://doi.org/10.6084/m9.figshare.12220493.v1).

\section{Conflicts of Interest}

No potential conflict of interest relevant to this article was reported.

\section{Author Contributions}

Laura Fusar-Poli conceptualized the study, supervised data extraction, and wrote the original draft of the manuscript. Alessandro Rodolico performed statistical analyses and participated to write the first draft of the manuscript. Serena Sturiale, Bianca Carotenuto, Antimo Natale, and Davide Arillotta performed data extraction and edited the manuscript. Spyridon Siafis helped in statistical analyses and contributed to write the manuscript. Maria Salvina Signorelli and Eugenio Aguglia supervised the project and edited the draft of the manuscript. All authors have read and approved the final version of the manuscript.

\section{ORCID}

Laura Fusar-Poli https://orcid.org/0000-0002-5847-6947 Alessandro Rodolico

https://orcid.org/0000-0003-2196-0601

Serena Sturiale https://orcid.org/0000-0001-6857-8907

Bianca Carotenuto https://orcid.org/0000-0003-2397-1507

Antimo Natale https://orcid.org/0000-0001-7931-6371

Davide Arillotta https://orcid.org/0000-0002-8843-0595

Spyridon Siafis https://orcid.org/0000-0001-8264-2039 Maria Salvina Signorelli

https://orcid.org/0000-0002-6941-9454

Eugenio Aguglia https://orcid.org/0000-0003-2146-7737

\section{REFERENCES}

1. Manning JT, Trivers RL, Thornhill R, Singh D. The 2nd: 4th digit ratio and asymmetry of hand performance in Jamaican children. Laterality 2000;5:121-132.

2. Mclntyre $\mathrm{MH}$, Ellison $\mathrm{PT}$, Lieberman DE, Demerath $\mathrm{E}$, Towne B. The development of sex differences in digital formula from infancy in the Fels Longitudinal Study. Proc Biol Sci 2005;272:1473-1479.

3. Manning JT. Digit ratio: a pointer to fertility, behavior, and health. Piscataway:Rutgers University Press;2002.

4. Lutchmaya S, Baron-Cohen S, Raggatt P, Knickmeyer R, Manning JT. 2nd to 4th digit ratios, fetal testosterone and 
estradiol. Early Hum Dev 2004;77:23-28.

5. Hönekopp J, Bartholdt L, Beier L, Liebert A. Second to fourth digit length ratio (2D:4D) and adult sex hormone levels: new data and a meta-analytic review. Psychoneuroendocrinology 2007;32:313-321.

6. Manning JT, Bundred PE, Newton DJ, Flanagan BF. The second to fourth digit ratio and variation in the androgen receptor gene. Evol Hum Behav 2003;24:399-405.

7. Auyeung B, Lombardo MV, Baron-Cohen S. Prenatal and postnatal hormone effects on the human brain and cognition. Pflugers Arch 2013;465:557-571.

8. Hönekopp J, Watson S. Meta-analysis of digit ratio 2D:4D shows greater sex difference in the right hand. Am J Hum Biol 2010;22:619-630.

9. Manning JT, Leinster SJ. re: The ratio of 2 nd to 4 th digit length and age at presentation of breast cancer: a link with prenatal oestrogen? Breast 2001;10:355-357.

10. Jung H, Kim KH, Yoon SJ, Kim TB. Second to fourth digit ratio: a predictor of prostate-specific antigen level and the presence of prostate cancer. BJU Int 2011;107:591-596.

11. Rahman AA, Lophatananon A, Stewart-Brown S, Harriss D, Anderson J, Parker $\mathrm{T}$, et al. Hand pattern indicates prostate cancer risk. Br J Cancer 2011;104:175-177.

12. Fink B, Manning JT, Neave N. The 2nd-4th digit ratio (2D:4D) and neck circumference: implications for risk factors in coronary heart disease. Int J Obes (Lond) 2006;30: 711-714.

13. Zhang W, Robertson J, Doherty S, Liu JJ, Maciewicz RA, Muir $\mathrm{KR}$, Doherty M. Index to ring finger length ratio and the risk of osteoarthritis. Arthritis Rheum 2008;58:137-144.

14. Fink B, Grammer K, Mitteroecker P, Gunz P, Schaefer K, Bookstein $\mathrm{FL}$, et al. Second to fourth digit ratio and face shape. Proc Biol Sci 2005;272:1995-2001.

15. Bang AK, Carlsen E, Holm M, Petersen JH, Skakkebaek NE, Jørgensen N. A study of finger lengths, semen quality and sex hormones in 360 young men from the general Danish population. Hum Reprod 2005;20:3109-3113.

16. Manning JT, Fink B. Is low digit ratio linked with late menarche? Evidence from the BBC internet study. Am J Hum Biol 2011;23:527-533.

17. Choi IH, Kim KH, Jung H, Yoon SJ, Kim SW, Kim TB. Second to fourth digit ratio: a predictor of adult penile length. Asian J Androl 2011;13:710-714.

18. Hönekopp J. Relationships between digit ratio 2D:4D and self-reported aggression and risk taking in an online study. Pers Individ Dif 2011;51:77-80.

19. Montag C, Bleek B, Breuer S, Prüss H, Richardt K, Cook S, et al. Prenatal testosterone and stuttering. Early Hum Dev 2015;91:43-46.

20. Peters M, Manning JT, Reimers S. The effects of sex, sexual orientation, and digit ratio (2D:4D) on mental rotation performance. Arch Sex Behav 2007;36:251-260.

21. Fink B, Manning JT, Neave N, Tan U. Second to fourth digit ratio and hand skill in Austrian children. Biol Psychol 2004; 67:375-384

22. Zhu YK, Li CB, Jin J, Wang JJ, Lachmann B, Sariyska R, et al. The 2D:4D ratio of the hand and schizotypal personality traits in schizophrenia patients and healthy control persons. Asian J Psychiatr 2014;9:67-72.

23. Hönekopp J, Schuster M. A meta-analysis on 2D:4D and athletic prowess: substantial relationships but neither hand out-predicts the other. Pers Individ Dif 2010;48:4-10.

24. Coates JM, Gurnell M, Rustichini A. Second-to-fourth digit ratio predicts success among high-frequency financial traders. Proc Natl Acad Sci U S A 2009;106:623-628.

25. Grimbos T, Dawood K, Burriss RP, Zucker KJ, Puts DA. Sexual orientation and the second to fourth finger length ratio: a meta-analysis in men and women. Behav Neurosci 2010;124:278-287.

26. Moher D, Liberati A, Tetzlaff J, Altman DG. Preferred reporting items for systematic reviews and meta-analyses: the PRISMA statement. Ann Intern Med 2009;151:264-269.

27. Fusar-Poli L, Rodolico A, Sturiale S, Carotenuto B, Natale A, Arillotta $\mathrm{D}$ et al. Second-to-fourth digit ratio (2D:4D): a potential biomarker for psychiatric disorders? - Supplementary Materials [dataset]. 2020 Apr 30. In: figshare [Internet]. London: Digital Science. 3.47 MB. Available from: https://doi.org/10.6084/m9.figshare.12220493.v1.

28. Stang A. Critical evaluation of the Newcastle-Ottawa scale for the assessment of the quality of nonrandomized studies in meta-analyses. Eur J Epidemiol 2010;25:603-605.

29. Borenstein M, Hedges LV, Higgins JP, Rothstein HR. Introduction to meta-analysis. Hoboken:John Wiley \& Sons;2011.

30. Higgins JPT, Green S. Cochrane handbook for systematic reviews of interventions. Oxford:Cochrane Collaboration;2011.

31. Falter CM, Plaisted KC, Davis G. Visuo-spatial processing in autism--testing the predictions of extreme male brain theory. J Autism Dev Disord 2008;38:507-515.

32. Bejerot S, Eriksson JM, Bonde S, Carlström K, Humble MB, Eriksson $\mathrm{E}$. The extreme male brain revisited: gender coherence in adults with autism spectrum disorder. BrJPsychiatry 2012;201:116-123.

33. Lai MC, Lombardo MV, Suckling J, Ruigrok AN, Chakrabarti B, Ecker C, et al. Biological sex affects the neurobiology of autism. Brain 2013;136(Pt 9):2799-2815.

34. Masuya Y, Okamoto Y, Inohara K, Matsumura Y, Fujioka T, Wada $Y$, et al. Sex-different abnormalities in the right second to fourth digit ratio in Japanese individuals with autism spectrum disorders. Mol Autism 2015;6:34.

35. Rohde MS, Georgescu AL, Vogeley K, Fimmers R, FalterWagner CM. Absence of sex differences in mental rotation performance in autism spectrum disorder. Autism 2018;22: 855-865.

36. Togo $\mathrm{S}$, Itahashi $\mathrm{T}$, Hashimoto R, Cai C, Kanai C, Kato N, et al. Fourth finger dependence of high-functioning autism spectrum disorder in multi-digit force coordination. Sci Rep 2019;9: 
1737.

37. Hauth I, de Bruijn YG, Staal W, Buitelaar JK, Rommelse NN. Testing the extreme male brain theory of autism spectrum disorder in a familial design. Autism Res 2014;7:491-500.

38. Sugie Y, Sugie H, Fukuda T, Osawa J. Study of HOXD genes in autism particularly regarding the ratio of second to fourth digit length. Brain Dev 2010;32:356-361.

39. Al-Zaid FS, Alhader AA, Al-Ayadhi LY. The second to fourth digit ratio (2D:4D) in Saudi boys with autism: a potential screening tool. Early Hum Dev 2015;91:413-415.

40. De Bruin El, Verheij F, Wiegman T, Ferdinand RF. Differences in finger length ratio between males with autism, pervasive developmental disorder-not otherwise specified, $A D H D$, and anxiety disorders. Dev Med Child Neurol 2006;48: 962-965.

41. Krajmer $P$, Spajdel M, Kubranska A, Ostatnikova D. 2D:4D finger ratio in Slovak autism spectrum population. Bratisl Lek Listy 2011;112:377-379.

42. Milne E, White S, Campbell R, Swettenham J, Hansen P, Ramus F. Motion and form coherence detection in autistic spectrum disorder: relationship to motor control and 2:4 digit ratio. J Autism Dev Disord 2006;36:225-237.

43. Lemiere J, Boets B, Danckaerts M. No association between the 2D:4D fetal testosterone marker and multidimensional attentional abilities in children with $A D H D$. Dev Med Child Neurol 2010;52:e202-e208.

44. Martel MM. Conscientiousness as a mediator of the association between masculinized finger-length ratios and attention-deficit/hyperactivity disorder (ADHD). J Child Psychol Psychiatry 2009;50:790-798.

45. McFadden D, Westhafer JG, Pasanen EG, Carlson CL, Tucker DM. Physiological evidence of hypermasculinization in boys with the inattentive type of attention-deficit/hyperactivity disorder (ADHD). Clin Neurosci Res 2005;5:233-245.

46. Baharara J, Hojjati M, Rasti H, Sarabi Jamab M. The Ratio of Second to Fourth Digit Length (2D:4D) in Children with Autistic Disorder. Int J Pediatr 2014;2:5-11.

47. Noipayak P. The ratio of 2nd and 4th digit length in autistic children. J Med Assoc Thai 2009;92:1040-1045.

48. Ypsilanti A, Ganou M, Koidou I, Grouios G. Digit ratio (2D:4D) in individuals with intellectual disability: investigating the role of testosterone in the establishment of cerebral lateralisation. Laterality 2008;13:527-544.

49. Buru E, Gözil R, Bahçelioğlu M, Özkan S, İşeri E. Evaluation of the hand anthropometric measurement in ADHD children and the possible clinical significance of the 2D:4D ratio. East J Med 2017;22:137-142.

50. Manning JT, Baron-Cohen S, Wheelwright S, Sanders G. The 2nd to 4th digit ratio and autism. Dev Med Child Neurol 2001;43:160-164.

51. Schieve LA, Tian L, Dowling N, Croen L, Hoover-Fong J, Alexander A, et al. Associations between the 2nd to 4th digit ratio and autism spectrum disorder in population-based samples of boys and girls: findings from the study to explore early development. J Autism Dev Disord 2018;48:2379-2395.

52. Divakaran A, Narayanaswamy JC, Kalmady SV, Narayan V, Rao NP, Venkatasubramanian G. Family history correlates of digit ratio abnormalities in schizophrenia. Indian J Psychol Med 2012;34:355-359.

53. Venkatasubramanian G, Arasappa R, Rao NP, Gangadhar $\mathrm{BN}$. Digit ratio (2D:4D) asymmetry and Schneiderian first rank symptoms: implications for cerebral lateralisation theories of schizophrenia. Laterality 2011;16:499-512.

54. Qian W, Huo Z, Lu H, Sheng Y, Geng Z, Ma Z. Digit ratio (2D:4D) in a Chinese population with schizophrenia. Early Hum Dev 2016;98:45-48.

55. Collinson SL, Lim M, Chaw JH, Verma S, Sim K, Rapisarda A, et al. Increased ratio of 2 nd to 4 th digit (2D:4D) in schizophrenia. Psychiatry Res 2010;176:8-12.

56. Akgül Ö, Küçükçoban O, Binbay T, Bora E, Alptekin K, Binnur Akdede B. Do clinical features relate to theory of mind, empathy and 2D:4D in schizophrenia?. Psychiatry and Clinical Psychopharmacology 2017;27:380-385.

57. Bolu A, Oznur T, Develi S, Gulsun M, Aydemir E, Alper M, et al. The ratios of 2 nd to 4 th digit may be a predictor of schizophrenia in male patients. Clin Anat 2015;28:551-556.

58. Paipa N, Stephan-Otto C, Cuevas-Esteban J, Núñez-Navarro A, Usall J, Brébion G. Second-to-fourth digit length ratio is associated with negative and affective symptoms in schizophrenia patients. Schizophr Res 2018;199:297-303.

59. Han C, Bae H, Lee YS, Won SD, Kim DJ. The ratio of 2nd to 4th digit length in Korean alcohol-dependent patients. Clin Psychopharmacol Neurosci 2016;14:148-152.

60. Lenz B, Mühle C, Braun B, Weinland C, Bouna-Pyrrou P, Behrens J, et al. Prenatal and adult androgen activities in alcohol dependence. Acta Psychiatr Scand 2017;136:96-107.

61. Canan F, Sogucak S, Karaca S, Tegin C, Gecici O, Kuloglu M. The second to fourth digit (2D:4D) ratios in patients with heroin use disorder. Heroin Addict Relat Clin Probl 2018;20:5-12.

62. Cicek IE, Cicek E, Demirel B, Ayhan MG, Varsak N, Özbek $\mathrm{SY}$, et al. Digit ratio (2D:4D), impulsiveness and aggression in male heroin addicts: a prospective controlled study. Pers Individ Dif 2017;117:1-5.

63. Kornhuber J, Erhard G, Lenz B, Kraus T, Sperling W, Bayerlein K, et al. Low digit ratio 2D:4D in alcohol dependent patients. PLoS One 2011;6:e19332.

64. Wallien MS, Zucker KJ, Steensma TD, Cohen-Kettenis PT. 2D:4D finger-length ratios in children and adults with gender identity disorder. Horm Behav 2008;54:450-454.

65. Schneider HJ, Pickel J, Stalla GK. Typical female 2nd-4th finger length (2D:4D) ratios in male-to-female transsexuals-possible implications for prenatal androgen exposure. Psychoneuroendocrinology 2006;31:265-269.

66. Vujović S, Popović S, Mrvošević Marojević L, Ivović M, Tančić-Gajić M, Stojanović M, et al. Finger length ratios in Serbian transsexuals. ScientificWorldlournal 2014;2014:763563. 
67. Kraemer B, Noll T, Delsignore A, Milos G, Schnyder U, Hepp U. Finger length ratio (2D:4D) in adults with gender identity disorder. Arch Sex Behav 2009;38:359-363.

68. Hisasue S, Sasaki S, Tsukamoto T, Horie S. The relationship between second-to-fourth digit ratio and female gender identity. J Sex Med 2012;9:2903-2910.

69. Leinung M, Wu C. The biologic basis of transgender identity: 2D:4D finger length ratios implicate a role for prenatal androgen activity. Endocr Pract 2017;23:669-671.

70. Sanwald S, Widenhorn-Müller K, Wernicke J, Sindermann C, Kiefer M, Montag C. Depression is associated with the absence of sex differences in the $2 D: 4 D$ ratio of the right hand. Front Psychiatry 2019;10:483.

71. Tegin C, Canan F, El-Mallakh RS. The 2nd to 4th digit ratios (2D:4D) in patients with bipolar disorder. J Affect Disord 2019;259:27-30

72. Berument SK, Rutter M, Lord C, Pickles A, Bailey A. Autism screening questionnaire: diagnostic validity. Br J Psychiatry 1999;175:444-451.

73. Auyeung B, Taylor K, Hackett G, Baron-Cohen S. Foetal testosterone and autistic traits in 18 to 24-month-old children. Mol Autism 2010;1:11.

74. Auyeung B, Baron-Cohen S, Ashwin E, Knickmeyer R, Taylor $\mathrm{K}$, Hackett G. Fetal testosterone and autistic traits. $\mathrm{Br} J$ Psychol 2009;100(Pt 1):1-22.

75. Baron-Cohen S, Auyeung B, Nørgaard-Pedersen B, Hougaard DM, Abdallah MW, Melgaard L, et al. Elevated fetal steroidogenic activity in autism. Mol Psychiatry 2015;20:369-376.

76. Kung KT, Spencer D, Pasterski V, Neufeld S, Glover V, O'Connor TG, et al. No relationship between prenatal androgen exposure and autistic traits: convergent evidence from studies of children with congenital adrenal hyperplasia and of amniotic testosterone concentrations in typically developing children. J Child Psychol Psychiatry 2016;57:14551462.

77. Chapman E, Baron-Cohen S, Auyeung B, Knickmeyer R, Taylor K, Hackett G. Fetal testosterone and empathy: evidence from the empathy quotient (EQ) and the "reading the mind in the eyes" test. Soc Neurosci 2006; 1:135-148.

78. Baron-Cohen S, Wheelwright S. The empathy quotient: an investigation of adults with Asperger syndrome or high functioning autism, and normal sex differences. J Autism Dev Disord 2004;34:163-175.

79. Manning JT, Baron-Cohen S, Wheelwright S, Fink B. Is digit ratio $(2 D: 4 D)$ related to systemizing and empathizing? Evidence from direct finger measurements reported in the BBC internet survey. Pers Individ Dif 2010;48:767-771.

80. Baron-Cohen S, Richler J, Bisarya D, Gurunathan N, Wheelwright S. The systemizing quotient: an investigation of adults with Asperger syndrome or high-functioning autism, and normal sex differences. Philos Trans R Soc Lond B Biol Sci 2003; 358:361-374.

81. Baron-Cohen S. The extreme male brain theory of autism
Trends Cogn Sci 2002;6:248-254.

82. Katsigianni M, Karageorgiou V, Lambrinoudaki I, Siristatidis C. Maternal polycystic ovarian syndrome in autism spectrum disorder: a systematic review and meta-analysis. $\mathrm{Mol}$ Psychiatry 2019;24:1787-1797.

83. Ingudomnukul E, Baron-Cohen S, Wheelwright $\mathrm{S}$, Knickmeyer R. Elevated rates of testosterone-related disorders in women with autism spectrum conditions. Horm Behav 2007;51:597604.

84. Voracek M. Digit ratio (2D:4D) as a marker for mental disorders: low (masculinized) 2D:4D in autism-spectrum disorders, high (feminized) 2D:4D in schizophrenic-spectrum disorders. Behav Brain Sci 2008;31:283-284.

85. Crespi B, Badcock C. Psychosis and autism as diametrical disorders of the social brain. Behav Brain Sci 2008;31:241-261.

86. Stenstrom E, Saad G, Nepomuceno MV, Mendenhall Z. Testosterone and domain-specific risk: digit ratios (2D:4D and rel2) as predictors of recreational, financial, and social risk-taking behaviors. Pers Individ Dif 2011;51:412-416.

87. Roberti JW. A review of behavioral and biological correlates of sensation seeking. J Res Pers 2004;38:256-279.

88. Campbell BC, Dreber A, Apicella CL, Eisenberg DT, Gray $\mathrm{PB}$, Little AC, et al. Testosterone exposure, dopaminergic reward, and sensation-seeking in young men. Physiol Behav 2010:99:451-456.

89. Kreek MJ, Nielsen DA, Butelman ER, LaForge KS. Genetic influences on impulsivity, risk taking, stress responsivity and vulnerability to drug abuse and addiction. Nat NeurosCi 2005;8:1450-1457.

90. Hönekopp J, Watson S. Meta-analysis of the relationship between digit-ratio 2D:4D and aggression. Pers Individ Dif 2011;51:381-386.

91. Hanoch Y, Gummerum M, Rolison J. Second-to-fourth digit ratio and impulsivity: a comparison between offenders and nonoffenders. PLoS One 2012;7:e47140.

92. Tomlinson MF, Brown M, Hoaken PNS. Recreational drug use and human aggressive behavior: a comprehensive review since 2003. Aggress Violent Behav 2016;27:9-29.

93. Eichler A, Heinrich $\mathrm{H}$, Moll GH, Beckmann MW, Goecke TW, Fasching PA, et al. Digit ratio (2D:4D) and behavioral symptoms in primary-school aged boys. Early Hum Dev 2018;119:1-7.

94. Hopfer C, Salomonsen-Sautel S, Mikulich-Gilbertson S, Min SJ, McQueen M, Crowley T, et al. Conduct disorder and initiation of substance use: a prospective longitudinal study. J Am Acad Child Adolesc Psychiatry 2013;52:511-518.e4.

95. Pasterski V, Zucker KJ, Hindmarsh PC, Hughes IA, Acerini C, Spencer D, et al. Increased cross-gender identification independent of gender role behavior in girls with congenital adrenal hyperplasia: results from a standardized assessment of 4- to 11-year-old children. Arch Sex Behav 2015;44:13631375 .

96. Jürgensen M, Kleinemeier E, Lux A, Steensma TD, Cohen- 
Kettenis PT, Hiort O, et al. Psychosexual development in adolescents and adults with disorders of sex development--results from the German Clinical Evaluation Study. J Sex Med 2013;10:2703-2714.

97. Steensma TD, Kreukels BP, de Vries AL, Cohen-Kettenis PT. Gender identity development in adolescence. Horm Behav 2013;64:288-297.

98. Surace T, Fusar-Poli L, Vozza L, Cavone V, Arcidiacono C, Mammano R, et al. Lifetime prevalence of suicidal ideation and suicidal behaviors in gender non-conforming youths: a meta-analysis. Eur Child Adolesc Psychiatry 2020. doi: 10.1007/s00787-020-01508-5. [Epub ahead of print]

99. Kornhuber J, Zenses EM, Lenz B, Stoessel C, Bouna-Pyrrou P, Rehbein $\mathrm{F}$, et al. Low 2D:4D values are associated with video game addiction. PLoS One 2013;8:e79539.

100. Quinton SJ, Smith AR, Joiner T. The 2 to 4 digit ratio (2D:4D) and eating disorder diagnosis in women. Pers Individ Dif 2011;51:402-405.

101. Siegmann EM, Bouna-Pyrrou P, Lenz B, Kornhuber J. Digit ratio $(2 D: 4 D)$ in relation to substance and computer use: a meta-analysis. J Neural Transm (Vienna) 2019;126:623-636. 